\title{
Phylogenomic Analysis of the Gammaproteobacterial Methanotrophs (Order Methylococcales) Calls for the Reclassification of Members at the Genus and Species Levels
}

\section{OPEN ACCESS}

Edited by: lain Sutcliffe,

Northumbria University, United Kingdom

Reviewed by:

Svetlana N. Dedysh,

Winogradsky Institute of Microbiology

(RAS), Russia

Claudia Knief,

Universität Bonn, Germany

*Correspondence:

Fabini D. Orata

orata@ualberta.ca

tThese authors have contributed equally to this work

Specialty section: This article was submitted to

Evolutionary and Genomic

Microbiology,

a section of the journal

Frontiers in Microbiology

Received: 05 October 2018 Accepted: 06 December 2018 Published: 19 December 2018

Citation:

Orata FD, Meier-Kolthoff JP, Sauvageau D and Stein LY (2018)

Phylogenomic Analysis of the Gammaproteobacterial Methanotrophs (Order Methylococcales) Calls for the Reclassification of Members at the Genus and Species Levels.

Front. Microbiol. 9:3162. doi: 10.3389/fmicb.2018.03162

\author{
Fabini D. Orata ${ }^{1,2 *}$, Jan P. Meier-Kolthoff ${ }^{3}$, Dominic Sauvageau ${ }^{1 \dagger}$ and Lisa Y. Stein ${ }^{2 \dagger}$
}

${ }^{1}$ Department of Chemical and Materials Engineering, University of Alberta, Edmonton, AB, Canada, ${ }^{2}$ Department of Biological Sciences, University of Alberta, Edmonton, AB, Canada, ${ }^{3}$ Department of Microorganisms, Leibniz Institute DSMZ - German Collection of Microorganisms and Cell Cultures, Braunschweig, Germany

The order Methylococcales constitutes the methanotrophs - bacteria that can metabolize methane, a potent greenhouse gas, as their sole source of energy. These bacteria are significant players in the global carbon cycle and can produce value-added products from methane, such as biopolymers, biofuels, and single-cell proteins for animal feed, among others. Previous studies using single-gene phylogenies have shown inconsistencies in the currently established taxonomic structure of this group. This study aimed to determine and resolve these issues by using whole-genome sequence analyses. Phylogenomic analysis and the use of similarity indexes for genomic comparisons - average amino acid identity, digital DNADNA hybridization $(\mathrm{dDDH})$, and average nucleotide identity $(\mathrm{ANI})$ - were performed on 91 Methylococcales genomes. Results suggest the reclassification of members at the genus and species levels. Firstly, to resolve polyphyly of the genus Methylomicrobium, Methylomicrobium alcaliphilum, "Methylomicrobium buryatense," Methylomicrobium japanense, Methylomicrobium kenyense, and Methylomicrobium pelagicum are reclassified to a newly proposed genus, Methylotuvimicrobium gen. nov.; they are therefore renamed to Methylotuvimicrobium alcaliphilum comb. nov., "Methylotuvimicrobium buryatense" comb. nov., Methylotuvimicrobium japanense comb. nov., Methylotuvimicrobium kenyense comb. nov., and Methylotuvimicrobium pelagicum comb. nov., respectively. Secondly, due to the phylogenetic affinity and phenotypic similarities of Methylosarcina lacus with Methylomicrobium agile and Methylomicrobium album, the reclassification of the former species to Methylomicrobium lacus comb. nov. is proposed. Thirdly, using established same-species delineation thresholds (70\% dDDH and 95\% ANI), Methylobacter whittenburyi is proposed to be a later heterotypic synonym of Methylobacter marinus (89\% dDDH and 99\% ANI). Also, the effectively but not validly published "Methylomonas denitrificans" was identified as Methylomonas methanica (92\% dDDH and 100\% ANI), indicating that the former is a later heterotypic synonym of the latter. Lastly, strains 
MC09, R-45363, and R-45371, currently identified as M. methanica, each represent a putative novel species of the genus Methylomonas $(21-35 \% \mathrm{dDDH}$ and $74-88 \%$ ANI against $M$. methanica) and were reclassified as Methylomonas sp. strains. It is imperative to resolve taxonomic inconsistencies within this group, first and foremost, to avoid confusion with ecological and evolutionary interpretations in subsequent studies.

Keywords: Gammaproteobacteria, Methylococcales, methanotroph, Methylotuvimicrobium gen. nov., genome
BLAST distance phylogeny, digital DNA-DNA hybridization, average nucleotide identity, average amino acid
identity

\section{INTRODUCTION}

Methanotrophs are microorganisms that can metabolize methane as their sole source of energy (Whittenbury et al., 1970; Bowman, 2018). They play a major role in the global carbon cycle (Cicerone and Oremland, 1988) and thrive in diverse ecosystems that have an influx of methane, including freshwater and marine sediments, wetlands, coal mine drainage waters, wastewater, groundwater, sewage sludge, most soils, and natural gas reserves (Hanson and Hanson, 1996; Knief, 2015; Bowman, 2018). Methane is 28 times more potent as a heat-trapping greenhouse gas than carbon dioxide (Edenhofer et al., 2014) and is a common low-value industrial by-product (Strong et al., 2015). On the other hand, this industrial waste can be converted by methanotrophs into value-added products such as biopolymers, biofuels, single-cell proteins for animal feed and human food, and nutrients for growth media, among others (Strong et al., 2015; Kalyuzhnaya and Xing, 2018).

Methanotrophs with validly published names belong to two classes, Gammaproteobacteria (also termed Type I and Type X) and Alphaproteobacteria (also termed Type II) (Bowman, 2018). Gammaproteobacterial methanotrophs belong to the order Methylococcales, which constitutes the families Methylococcaceae, Methylothermaceae, and Crenotrichaceae, currently including 42 species with validly published names from 19 genera (Parte, 2014). Most of the identified isolates belong to the family Methylococcaceae, which consists of 16 genera and 39 species. Family Methylothermaceae consists of two genera and two species, and family Crenotrichaceae consists of a single genus and species (Parte, 2014). These taxa were circumscribed mainly based on phylogeny of $16 \mathrm{~S}$ rRNA gene sequences (Bowman, 2018). The oxidation of methane to methanol is performed by the particulate methane monooxygenase (pMMO), present in most methanotrophs, and the PmoA subunit has also been widely used in phylogenetic analyses (Knief, 2015; Bowman, 2018). Taxonomy within this order has been questioned and revised significantly (Bowman et al., 1993, 1995; Bowman, 2018). In some cases, 16S rRNA and PmoA phylogenies are not congruent and certain genera appear as polyphyletic (e.g., Methylobacter and Methylomicrobium) or paraphyletic (e.g., Methylosarcina) (Knief, 2015). A group or taxon is polyphyletic if they are derived from more than one common ancestor; it is paraphyletic if they are derived from a common ancestor, but the taxon does not include all descendants of that common ancestor. These are in contrast to a monophyletic taxon, which is composed of all descendants of a single common ancestor. The monophyletic nature of members in a phylogenetic tree is the main criterion for defining a taxon (Rosselló-Móra and Amann, 2001).

With the advent of next-generation sequencing, phylogeny using whole-genome sequences, as opposed to single genes, has become an important tool for the delineation of prokaryotic taxa and clarification of taxonomic inconsistencies (Chun and Rainey, 2014; Garrity, 2016; Chun et al., 2018; Parks et al., 2018). Recent studies of the phyla Actinobacteria and Bacteroidetes mainly used a genome-based phylogeny to reclassify organisms at various taxonomic ranks, despite inconsistencies in phenotypic information (Hahnke et al., 2016; Nouioui et al., 2018). Although several major features are still distinctive between Type I and Type II methanotrophs (e.g., one-carbon assimilation pathway, type of intracytoplasmic membrane arrangement, etc.), the characterization of several new genera and species made initially distinct traits no longer indicative for one or the other type (e.g., signature fatty acids, formation of resting stages, optimum growth temperature, etc.) (Knief, 2015). The availability of whole-genome sequences has also provided defined delineation standards through genomic comparisons, more so for species than higher ranks (Garrity, 2016). Experimental DNA-DNA hybridization (DDH) is now being replaced by in silico (digital) DDH (dDDH) (Auch et al., 2010; MeierKolthoff et al., 2013), yet still maintaining the cut-off of $70 \%$ hybridization for two genomes to belong to the same species (Goris et al., 2007). Similarly, average nucleotide identity (ANI) also measures the nucleotide-level similarity between two genomes (Richter and Rosselló-Móra, 2009), which represent the same species if they have at least 95\% ANI (Goris et al., 2007). The use of ANI had uncovered high levels of genomic similarity between methanotrophic species Methylomicrobium agile and Methylomicrobium album (Kalyuzhnaya, 2016a), as well as Methylobacter marinus and Methylobacter whittenburyi (Collins et al., 2017), therefore questioning their identities. Although not as widely used, average amino acid identity (AAI) (Konstantinidis and Tiedje, 2005) and the percentage of conserved proteins (POCP) (Qin et al., 2014), which both measure amino acid-level genomic similarity between proteincoding regions, have been proposed to delineate organisms at the genus level.

This study aimed to establish a whole-genome phylogeny for currently available Methylococcales genomes, supplemented with genome-based similarity indexes to determine and resolve taxonomic inconsistencies within this group of microorganisms. 


\section{MATERIALS AND METHODS}

\section{S rRNA, PmoA, and Whole-Genome Sequences Used in This Study}

Nucleotide or amino acid sequences of the 16S rRNA and pmoA genes from 49 type and representative strains of Methylococcales, including species with effectively but not validly published names, were obtained from the NCBI GenBank (Benson et al., 2018) or MicroScope (Médigue et al., 2017) databases (Supplementary Table S1). Additionally, a total of 91 whole-genome sequences were obtained from the NCBI Microbial Genomes (Tatusova et al., 2014) or MicroScope (Médigue et al., 2017) databases, including 86,3 , and 2 genomes previously identified to belong to Methylococcaceae, Crenotrichaceae, and Methylothermaceae, respectively (Supplementary Table S2). Annotated plasmid sequences, if present, were excluded from any analysis. An additional set of sequences from two species belonging to the genus Methylosinus (Type II methanotroph) was chosen as outgroup for phylogenetic analyses.

\section{S rRNA and PmoA Phylogenies}

The 16S rRNA and PmoA sequences were aligned with MAFFT 1.3.7 (Katoh and Standley, 2013) in Geneious 11.1.3 (Kearse et al., 2012). Poorly aligned positions were eliminated using GBlocks 0.91b (Castresana, 2000). The final alignments, with 1,469 nucleotide positions for 16S rRNA and 243 amino acid positions for PmoA, were used to reconstruct maximum-likelihood phylogenetic trees with RAxML 8.2.12 (Stamatakis, 2014). The GTR (general time reversible) nucleotide substitution model or WAG (Whelan and Goldman) amino acid substitution model and the gamma model of rate heterogeneity were used. Robustness of branching was estimated with 100 bootstrap replicates. Nodes with $50 \%$ or less bootstrap support were collapsed to polytomies using TreeCollapserCL 4.0 (Hodcroft, 2016). The trees and support values were visualized using iTOL 4.2 (Letunic and Bork, 2016) or FigTree 1.4.3 (Rambaut, 2007).

\section{Whole-Genome Phylogeny}

The high-throughput version (Meier-Kolthoff et al., 2014a) of the Genome BLAST Distance Phylogeny (GBDP) approach (Henz et al., 2005; Meier-Kolthoff et al., 2013) was used to infer phylogenies from the genome sequences (restricted to coding regions) in conjunction with BLAST+ 2.2.3 (Camacho et al., 2009) in BLASTN mode with default parameters except for an $E$-value filter of $10^{-8}$ (MeierKolthoff et al., 2014a). The greedy-with-trimming GBDP algorithm was applied in conjunction with formula $d_{5}$ and subjected to 100 pseudo-bootstrap replicates (MeierKolthoff et al., 2013, 2014a). FastME 2.1.4 (Lefort et al., 2015) was used to infer phylogenetic trees from the original and pseudo-bootstrapped intergenomic distance matrices. The tree and support values were visualized using iTOL 4.2 (Letunic and Bork, 2016) or FigTree 1.4.3 (Rambaut, 2007).

\section{Genome-Based Similarity Indexes for Genus Delineation}

For the clarification of genus affiliations, AAI (Konstantinidis and Tiedje, 2005) and POCP (Qin et al., 2014) were used for amino acid-level comparisons for every pairwise combination of genomes. AAI was determined by calculating the mean protein sequence similarity of all protein-coding genes shared between strains (Konstantinidis and Tiedje, 2005). This was done with CompareM 0.0.21 (Parks, 2017), which employed Prodigal 2.6.3 for gene calling (Hyatt et al., 2010) and DIAMOND 0.9.19 to perform sequence similarity searches (Buchfink et al., 2015), using default BLASTP parameters (i.e., $10^{-5} \mathrm{E}$-value, $30 \%$ sequence identity cut-off, and $\geq 70 \%$ alignment length) to define bidirectional best BLAST hits between genomes. Also, using CompareM 0.0.21 (Parks, 2017), the number of orthologous genes shared between two genomes was determined. This was subsequently used to calculate POCP using the formula $[(2 \times \mathrm{S}) /(\mathrm{T} 1+\mathrm{T} 2)] \times 100 \%$, where $S$ represents the number of genes shared between genomes and T1 and T2 represent the total number of proteins in the two genomes being compared (Qin et al., 2014).

\section{Genome-Based Similarity Indexes for Species Delineation}

For the clarification of species affiliations, dDDH (Auch et al., 2010; Meier-Kolthoff et al., 2013) and ANI (Goris et al., 2007) were used for nucleotide-level comparisons for every pairwise combination of genomes. $\mathrm{dDDH}$ was calculated using the recommended settings (formula 2) of the Genome-to-Genome Distance Calculator 2.1 (Auch et al., 2010; Meier-Kolthoff et al., 2013). ANI was calculated as described by Goris et al. (2007) and using default parameters in JSpecies 1.2.1 (Richter and Rosselló-Móra, 2009). Briefly, the query genome was cut into $1,020 \mathrm{bp}$ fragments, and these were used to search against the reference genome using BLASTN with a sequence identity cut-off and an alignment length minimum as above. The query and reference genomes were then reversed. The bidirectional best BLAST hits for each fragment were reported as the average percent identity from all comparisons. Two genomes belonging to the same species would have a $\mathrm{dDDH}$ of at least $70 \%$, which corresponds to at least $95 \%$ ANI (Goris et al., 2007; Auch et al., 2010; Meier-Kolthoff et al., 2013).

\section{Selection of Phenotypes to Support Reclassifications}

In cases were phenotypic information was needed to clarify taxon affiliation, data on several phenotypic characteristics commonly tested between organisms were collected from the original isolation papers and the Bergey's Manual of Systematics of Archaea and Bacteria (Table 1; Bowman, 2016a,b; Hirayama, 2016; Kalyuzhnaya, 2016a,b; Collins et al., 2017; Bowman, 2018). Data missing from isolation papers and information on isolates that are not type strains were retrieved from other references as stipulated. 


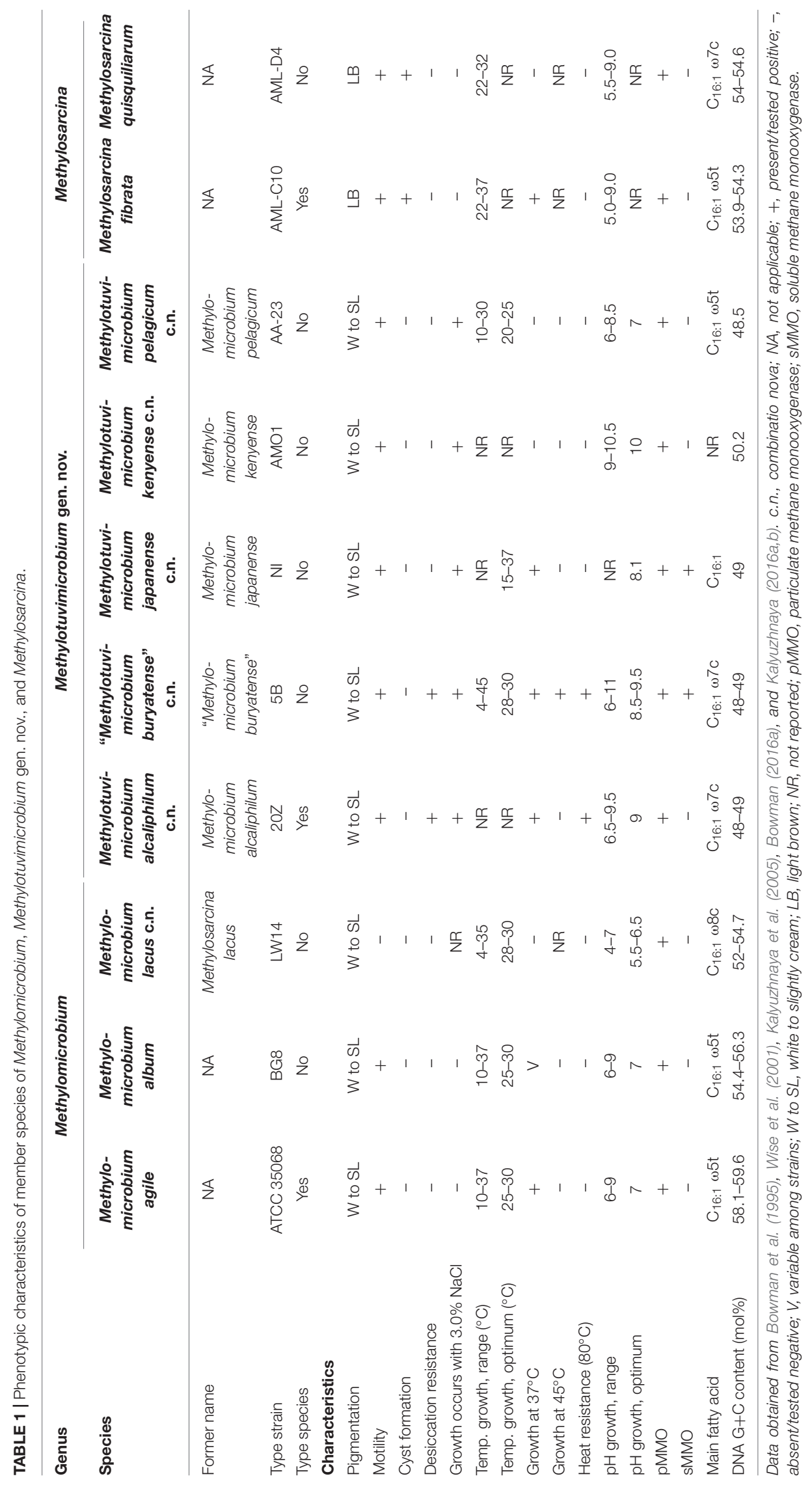




\section{RESULTS AND DISCUSSION}

To determine the impact of using the $16 \mathrm{~S}$ rRNA and $p m o A$ genes as main molecular markers for defining new methanotrophic taxa, phylogenetic analyses were performed using sequences from all 49 currently known type and representative strains belonging to the order Methylococcales, including those with effectively but not validly published species names (Supplementary Table S1). The phylogenetic trees show low bootstrap support overall (Figure 1 and Supplementary Figure S1). When nodes with bootstrap support below $50 \%$ are collapsed, the poorly resolved tree backbones are evident (Figure 1). One should take caution when interpreting relationships from these trees, always keeping in mind that the taxon of interest should correspond to a highly supported monophyletic clade. It is also important to note that the use of these gene markers alone should not describe a taxon, but they can provide the first indication that an isolate could belong to a novel or already existing taxon (Tindall et al., 2010).

A whole-genome-based phylogenetic tree was then reconstructed from 91 Methylococcales genomes via the GBDP approach (Henz et al., 2005; Meier-Kolthoff et al., 2013). The inferred tree was used to assess the monophyletic status of members supposedly belonging to the same taxon. Unlike the $16 \mathrm{~S}$ rRNA and PmoA trees (Figure 1 and Supplementary Figure S1), the genome phylogeny revealed robust bootstrap support with most branches having maximum support (Figure 2). This highlighted apparent taxonomic inconsistencies, but also allowed for the confident establishment of relationships within Methylococcales.

\section{Taxonomic Structure at the Family Level Within Methylococcales}

The reconstructed genome phylogeny reveals three lineages of gammaproteobacterial methanotrophs (Figure 2). This is because the clade consisting of the genera Methylococcus, Methyloterricola, Methylomagnum, Methylogaea, and Methylocaldum (i.e., Type X methanotrophs) is not monophyletic with the rest of family Methylococcaceae. These three lineages were also shown by the Genome Taxonomy Database (GTDB) phylogeny reconstructed from 120 ubiquitous single-copy protein-coding genes (Parks et al., 2018). As such, Parks et al. (2018) proposed the transference of the majority of Methylococcaceae members to a different family. The three family lineages were therefore named as "Methylomonadaceae," Methylococcaceae, and Methylothermaceae (Supplementary Figure S2; Parks et al., 2018), corresponding to Type Ia, Ib (or X), and Ic, respectively (Knief, 2015; Bowman, 2016a).

The Type X and Methylothermaceae clades appear monophyletic in the genome-based tree (Figure 2), and it can be argued that members of these clades could be merged into one family. Members of these lineages are mesophilic to thermophilic and form dessication-resistant Azotobacter-type cysts, unlike members of "Methylomonadaceae" which are

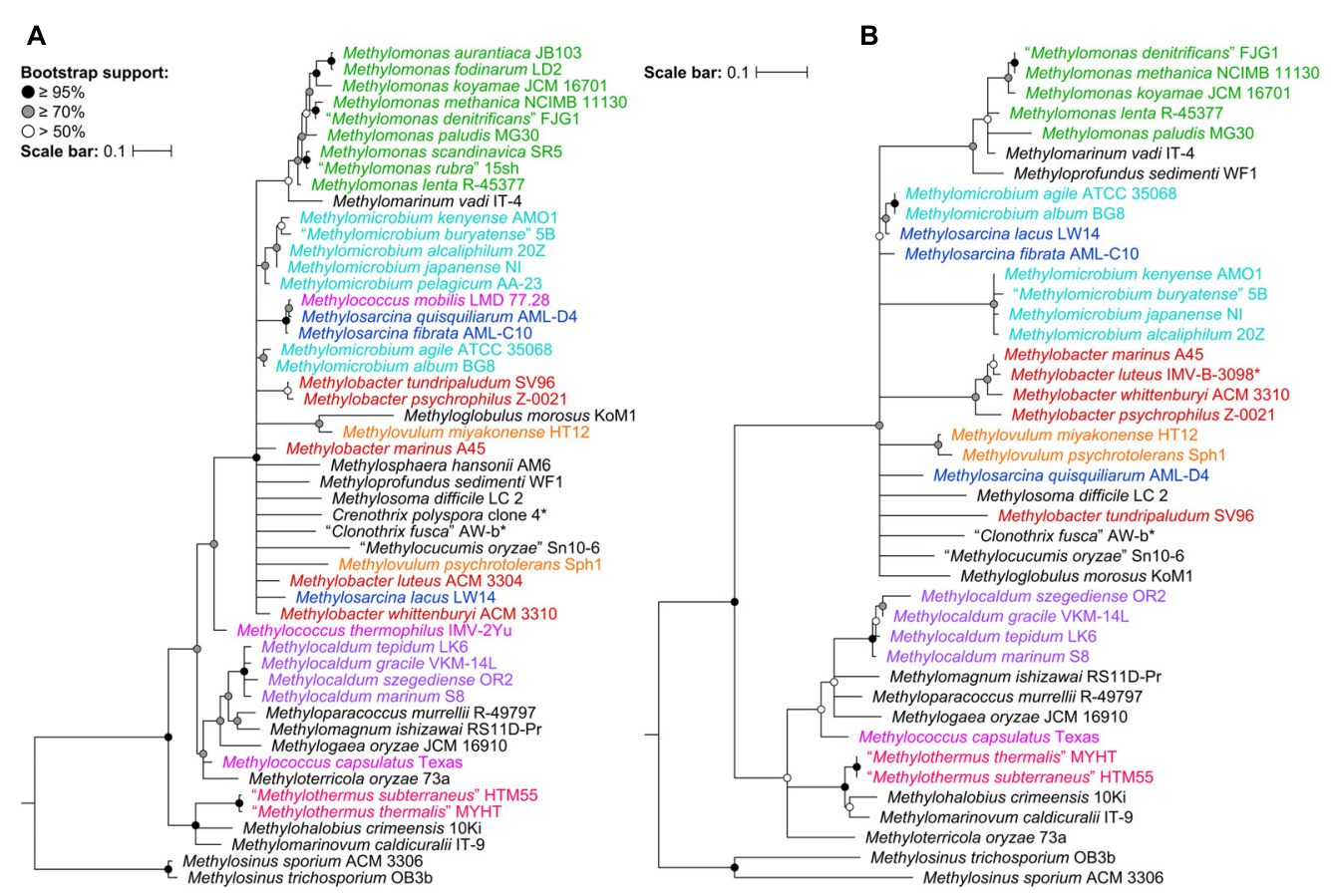

FIGURE 1 | The phylogenetic relationship of Methylococcales type and representative strains based on (A) $16 \mathrm{~S}$ rRNA and (B) PmoA sequences. The maximum-likelihood trees were constructed from the alignments of (A) 16S rRNA (1,469 nucleotide positions) and (B) PmoA (243 amino acid positions) sequences. Methylosinus was chosen as outgroup. Nodes with $50 \%$ or less bootstrap support are collapsed. Bootstrap support is indicated on the nodes as black ( $\geq 95 \%$ ), gray $(\geq 70 \%)$, or white $(>50 \%)$ circles. The scale bars represent $\mathbf{( A )}$ nucleotide or (B) amino acid substitutions per site. Genera with at least two members are colored; genera with single members (and outgroup) are black. Asterisks indicate non-type strains. 


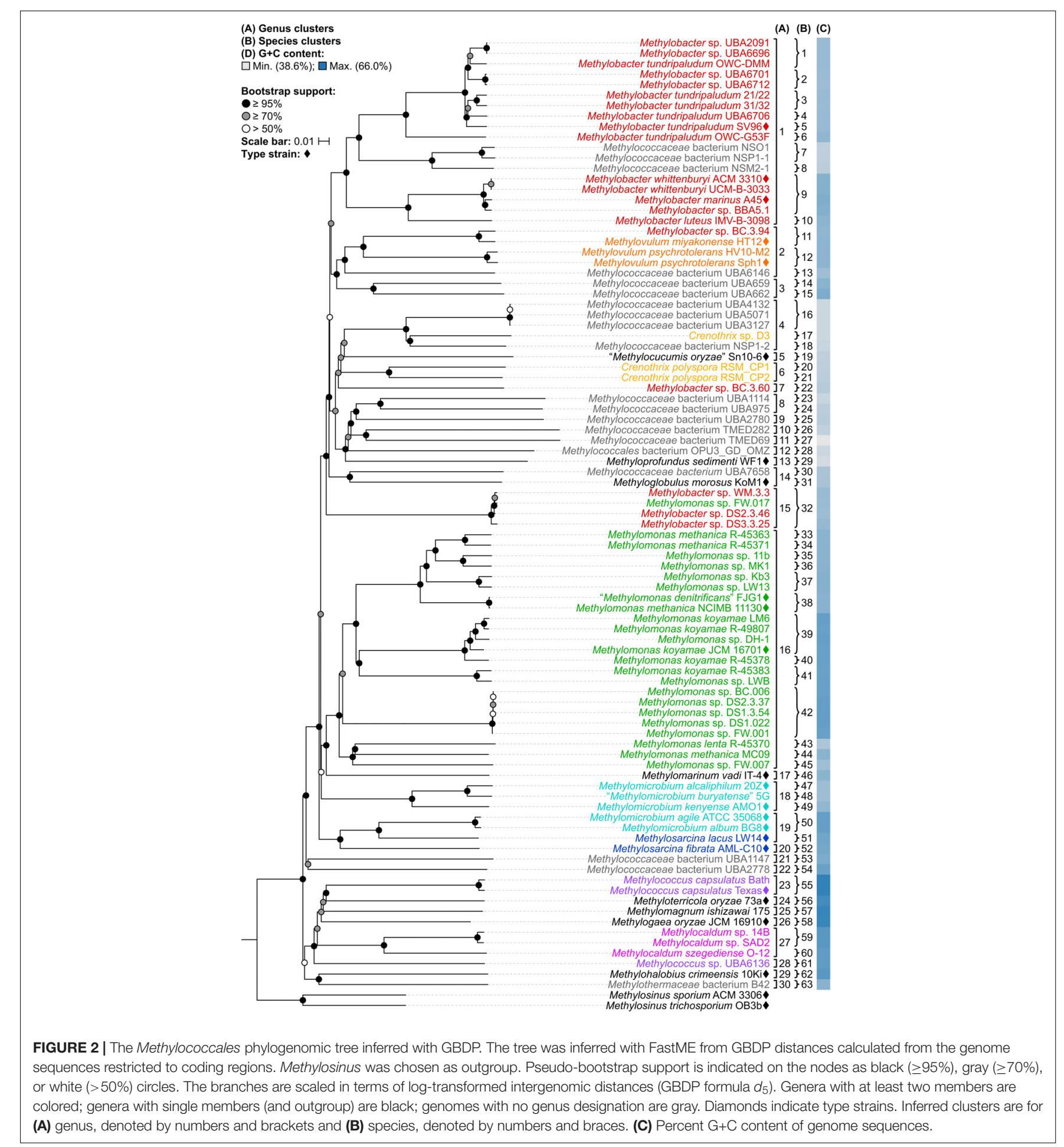

psychrophilic to mesophilic and form non-desiccation-resistant "immature" Azotobacter-type cysts (Bowman, 2016a). On the other hand, members of Methylothermaceae can be distinguished from Methylococcaceae by their abundance of $\mathrm{C}_{18: 1}$ fatty acids (Hirayama et al., 2014; Hirayama, 2016), a typical characteristic of Type II methanotrophs (Hanson and Hanson, 1996). Methylothermaceae consists of three genera, "Methylothermus,"
Methylomarinovum, and Methylohalobius, but only the latter has a genome-sequenced type strain. Thus, reclassification, if warranted, is premature at this point without complete genomic information.

Despite the lack of a cultivated representative, Crenothrix polyspora is a validly published species name (Ad Hoc Committee of the Judicial Commission of the ICSB, 1989). The species is 
listed under family Crenotrichaceae in the List of Prokaryotic Names with Standing in Nomenclature (Parte, 2014) but has been transferred to Methylococcaceae in the most recent edition of the Bergey's Manual of Systematics of Archaea and Bacteria (Bowman, 2016a). Although C. polyspora is multicellular and filamentous, its assignment to Methylococcaceae is consistent with the occurrence of intracytoplasmic membrane stacks and their arrangement as vesicular discs (Völker et al., 1977; Stoecker et al., 2006), as well as the placement of the species within the family based on 16S rRNA phylogeny (Figure 1A and Supplementary Figure S1A; Völker et al., 1977; Stoecker et al., 2006; Vigliotta et al., 2007; Knief, 2015; Bowman, 2016a; Oswald et al., 2017). Indeed, the genome phylogeny shows the three Crenothrix genomes (C. polyspora RSM_CP1 and RSM_CP2 and Crenothrix sp. D3) positioned well within Methylococcaceae with high bootstrap support (Figure 2). To our knowledge, this is the first confirmation by whole-genome phylogeny of Crenothrix belonging to Methylococcaceae. Additionally, these three genomes are not monophyletic, and the consequence of this polyphyly in terms of genus nomenclature is discussed below.

A fourth family, "Cycloclasticaceae," was introduced by the GTDB taxonomy as a member of order Methylococcales (Parks et al., 2018). This family includes the species Cycloclasticus pugetii, a gammaproteobacterium that does not use methane or methanol but is instead capable of growing on aromatic hydrocarbons as sole sources of organic carbon (Dyksterhouse et al., 1995). The genus Cycloclasticus is currently a member of the family Piscirickettsiaceae (Parte, 2014; Geiselbrecht, 2015). Interestingly, Bowman (2016a, 2018) noted the paraphyly of Methylococcales to a number of other taxa of the class Gammaproteobacteria (e.g., Cycloclasticus and Methylophaga) based on 16S rRNA phylogeny. This raises the possible inclusion of non-methanotrophic bacteria into Methylococcales, which currently only includes methanotrophs (Bowman, 2018), and the potential reorganization of taxonomic structure at the family and higher levels. The presence of non-methanotrophic members in the same family has been identified for the Type II methanotrophs (i.e., Beijerinckiaceae and Methylocystaceae of the order Rhizobiales) (Parte, 2014). Reorganization and reclassification of this level warrants a larger-scale genome sequencing effort, especially of unsequenced type strains within Methylococcales and all closely related taxa. Such effort in sequencing the genomes of type strains and making them publicly available is underway, such as the massive Genomic Encyclopedia of Bacteria and Archaea sequencing project (Wu et al., 2009; Kyrpides et al., 2014; Whitman et al., 2015; Mukherjee et al., 2017).

\section{Use of POCP vs. AAl for the Delineation of Genera}

Taxonomic reorganization is required at the genus level because of several polyphyletic (e.g., Methylobacter, Crenothrix, Methylomonas, Methylomicrobium, and Methylococcus) and paraphyletic (e.g., Methylovulum and Methylosarcina) genera (Figure 2). Reorganization requires setting criteria for the amount of diversity allowed within genera, keeping in mind the use of a genome-based phylogeny as a primary guideline to identify clades that (i) are monophyletic (Rosselló-Móra and Amann, 2001) and (ii) would require the fewest number of changes from the current taxonomy. Here, the viability of genome-based similarity indexes, POCP (Qin et al., 2014) and AAI (Konstantinidis and Tiedje, 2005), as supplements to genome phylogeny to infer genera were examined.

A fixed genus boundary of 50\% POCP has been proposed (Qin et al., 2014). Applying this boundary shows several pairwise comparisons of at least 50\% POCP (Figure 3 and Supplementary Table S3) that would automatically violate the monophyly rule for taxon delineation (Rosselló-Móra and Amann, 2001). Taking into consideration comparisons with at least 50\% POCP that also exhibited monophyly in the genome phylogeny, inferred genus-level clusters would require splitting previously described species from the same genus into different genera (Supplementary Figure S3). For example, the inferred Methylobacter clade, the largest monophyletic clade formed by the majority of Methylobacter strains (Figure 2), would be split into five genera and separate type strains Methylobacter tundripaludum SV96 ${ }^{\mathrm{T}}$ (Wartiainen et al., 2006) from M. whittenburyi ACM $3310^{\mathrm{T}}$ and M. marinus $\mathrm{A} 45^{\mathrm{T}}$ (Bowman et al., 1993; Supplementary Figure S3). The same could be said for the inferred Methylomonas clade, the largest monophyletic clade formed by the majority of Methylomonas strains (Figure 2), which would be split into seven genera. It would separate Methylomonas methanica NCIMB $11130^{\mathrm{T}}$ (Bowman, 2016b) and "Methylomonas denitrificans" $\mathrm{FJG1}^{\mathrm{T}}$ (Kits et al., 2015) from Methylomonas koyamae JCM $16701^{\mathrm{T}}$ (Ogiso et al., 2012; Supplementary Figure S3). On the other hand, this POCP threshold would merge Methylococcus capsulatus Texas $^{\mathrm{T}}$ (Foster and Davis, 1966) and Methyloterricola oryzae $73 \mathrm{a}^{\mathrm{T}}$ (Frindte et al., 2017) into the same genus. In this context, the 50\% POCP boundary is not an appropriate metric to delineate genera within Methylococcaceae. The use of the POCP has, similarly, been shown to be ineffective in delineating genera within the families Bacillaceae (Aliyu et al., 2016), Burkholderiaceae (Lopes-Santos et al., 2017), Neisseriaceae (Li et al., 2017), and Rhodobacteraceae (Wirth and Whitman, 2018), among others.

Another tool proposed for delimiting taxonomic ranks at the genus level is AAI (Konstantinidis and Tiedje, 2005). However, prokaryotic taxa exhibit a range of AAI values, making distinct boundaries difficult to define (Konstantinidis and Tiedje, 2005; Luo et al., 2014). AAI comparisons by Luo et al. (2014) of related but different genera typically ranged from 60 to $80 \%$. We determined pairwise AAI values for the 91 Methylococcales genomes investigated (Figure 3 and Supplementary Table S3). Over $70 \%$ of comparisons had at least $60 \%$ AAI, which would result in the collapse of the majority of genomes into a single genus. To minimize changes to the current nomenclature, this inferred lower AAI boundary (Luo et al., 2014) cannot be applied to discriminate genera. We then looked at the AAI range of the two most well-represented monophyletic clades, Methylobacter and Methylomonas (genus clusters 1 and 16, respectively) (Figure 2). In a previous study with a limited number of five to six genomes, the AAI ranges for these genera were determined to be $70-95 \%$ and $75-90 \%$, respectively (Skennerton et al., 2015). 


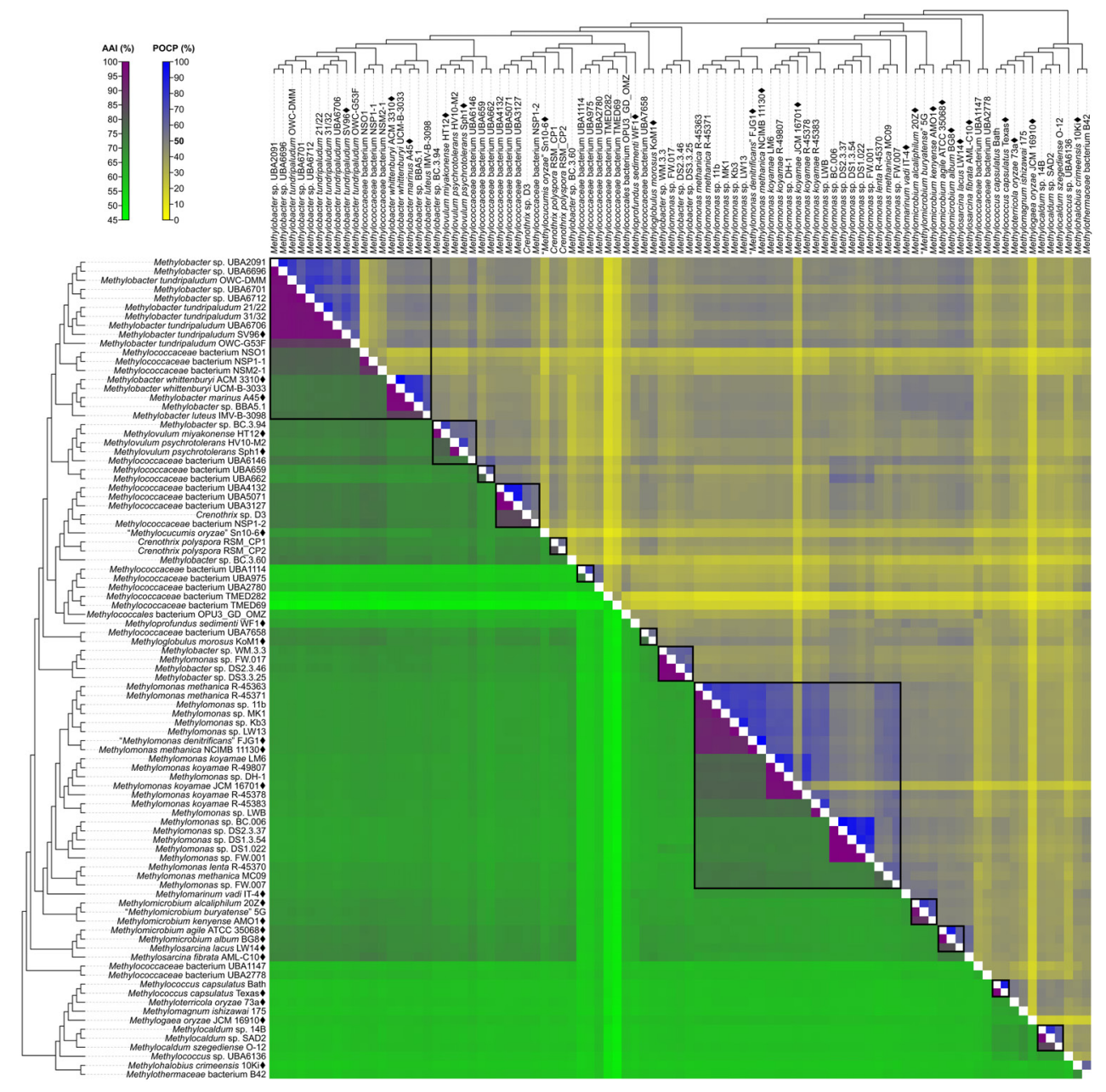

FIGURE 3 | AAI and POCP from pairwise whole-genome comparisons. The heat map shows AAl and POCP values between genomes, along with the tree cladogram to show relationships. Boxed regions indicate inferred genus clusters with at least two members based on AAl comparisons, as well as monophyly in the genome-based phylogeny. POCP was not used to infer genera.

In our analysis, the AAI values obtained ranged from 74 to $100 \%$ and 71 to $100 \%$ from 18 and 23 genomes, respectively (Supplementary Table S3 and Supplementary Figure S3). For the Methylobacter clade, going below 74\% AAI would include several genomes (Methylobacter sp. BC.3.94, Methylovulum miyakonense $\mathrm{HT}_{12}{ }^{\mathrm{T}}$, and Methylococcaceae bacterium UBA6146) in the genus that would result in paraphyly, which should be avoided.

The use of $71 \%$ AAI as the lower genus limit resulted in 30 inferred monophyletic genera that maintained most of the current classifications for the identified genomes (Figure 2). The AAI ranges within the different inferred genera varied (Supplementary Table S3 and Supplementary Figure S3). The clades containing Methylovulum (genus cluster 2), Crenothrix sp. D3 (genus cluster 4), and Methylocaldum (genus cluster 27) (Figure 2) had AAI ranges of $73-100 \%, 84-100 \%$, and $84-100 \%$, respectively. The variable AAI ranges among the inferred genus clades may be due to a lack of representation of some genera, but variations in AAI can be expected since different prokaryotic taxa, even those that are closely related, can evolve at different rates due to differences in responses to evolutionary and ecological processes (Ramette and Tiedje, 2007). These AAI ranges may eventually change as more genomes from identified isolates become available in the future, allowing for an even better resolution of individual genus-level clades.

As mentioned previously, the three Crenothrix genomes are not monophyletic, with Crenothrix sp. D3 (Oswald et al., 2017) instead exhibiting affinity with "Methylocucumis oryzae" Sn106 (Pandit et al., 2018; Figure 2). The initial assignment of genome D3 to Crenothrix was ambiguous since it is separate from C. polyspora in the $16 \mathrm{~S}$ rRNA phylogeny and $60 \%$ AAI was used for genus prediction (Oswald et al., 2017). Genome D3 is monophyletic with several other genomes only designated as Methylococcaceae bacterium, UBA4132, UBA5071, UBA3127, and NSP1-2 (genus cluster 4). As inferred by the GTDB taxonomy (Parks et al., 2018), this clade is separate from C. polyspora RSM_CP1 and RSM_CP2 (genus cluster 6). Crenothrix sp. D3 is thus renamed to Methylococcaceae bacterium 
D3, since only one clade can keep the genus name. Genomes RSM_CP1 and RSM_CP2 remained as Crenothrix based solely on their phylogenetic affinity with other 16S rRNA genes from C. polyspora (Oswald et al., 2017). All sequenced members of these clades are metagenome-assembled genomes (MAGs) obtained from various methane sinks (Oswald et al., 2017; Parks et al., 2017; Smith et al., 2018), so formal genus descriptions cannot be performed until known isolates exhibiting affinity within these clades become available (Tindall et al., 2010).

A similar case was seen with Methylococcus, where M. capsulatus Texas $^{\mathrm{T}}$ and Bath are monophyletic (genus cluster 23) but are positioned separately from Methylococcus sp. UBA6136 (genus cluster 28) (Figure 2), a MAG derived from an oil sands tailings pond metagenome (Parks et al., 2017). The latter is renamed Methylococcaceae bacterium UBA6136 as it is currently the sole member of a yet to be described genus.

The Methylovulum clade (genus cluster 2) consists of type strains M. miyakonense HT12 ${ }^{\mathrm{T}}$ (Iguchi et al., 2011) and Methylovulum psychrotolerans Sph $1^{\mathrm{T}}$ (Oshkin et al., 2016) and strain HV10-M2 (Mateos-Rivera et al., 2018; Figure 2). This clade also includes Methylobacter sp. BC.3.94 and Methylococcaceae bacterium UBA6146, both derived from wastewater metagenomes from groundwater (Zhang et al., 2017) and an oil sands tailings pond (Parks et al., 2017), respectively. Accordingly, the latter strains are renamed Methylovulum sp. BC.3.94 and Methylovulum sp. UBA6146.

The two genomes representing Methylothermaceae, Methylohalobius crimeensis $10 \mathrm{Ki}^{\mathrm{T}}$ (Heyer et al., 2005) and Methylothermaceae bacterium B42, are monophyletic but likely represent different genera (genus clusters 29 and 30, respectively) (Figure 2), as determined previously by Skennerton et al. (2015) and the GTDB taxonomy (Parks et al., 2018), since AAI between the two is only $69 \%$ (Supplementary Table S3).

\section{Resolving Genus-Level Taxonomic Inconsistencies Between Methylomicrobium and Methylosarcina}

Our whole-genome phylogeny shows the five Methylomicrobium strains to be polyphyletic (Figure 2). M. agile ATCC $35068^{\mathrm{T}}$ and $M$. album $\mathrm{BG8}^{\mathrm{T}}$ are separate from Methylomicrobium alcaliphilum $20 \mathrm{Z}^{\mathrm{T}}$, "Methylomicrobium buryatense" $5 \mathrm{G}$, and Methylomicrobium kenyense $\mathrm{AMO}^{\mathrm{T}}$. AAI between these clades is $66-67 \%$ and are thus proposed to represent different genera (Supplementary Table S3), consistent with the GTDB taxonomy (Parks et al., 2018). We propose the transference of $M$. alcaliphilum, "M. buryatense," and M. kenyense to a genus different from $M$. agile and M. album. According to Rule 39a (section 7, chapter 3) of the International Code of Nomenclature of Bacteria: Bacteriological Code (Lapage et al., 1992), if a genus is divided into two or more genera, the generic name must be retained for one of them based on name priority by publication date (Rules 23a and 23b, section 5) and/or type designation (Rule 39b, section 7). Therefore, we propose the reclassification of $M$. alcaliphilum, "M. buryatense," and $M$. kenyense to a novel genus, Methylotuvimicrobium gen. nov. They should then be renamed Methylotuvimicrobium alcaliphilum comb. nov., "Methylotuvimicrobium buryatense" comb. nov., and Methylotuvimicrobium kenyense comb. nov., respectively, since they were identified (ca. 2001 and 2008) (Kaluzhnaya et al., 2001; Kalyuzhnaya et al., 2008) after M. agile and M. album (ca. 1995) and since M. agile is the type species of the genus (Bowman et al., 1995).

Unfortunately, the genomes of three closely related type strains, “M. buryatense" $5 \mathrm{~B}^{\mathrm{T}}$ (Kaluzhnaya et al., 2001), Methylomicrobium japanense $\mathrm{NI}^{\mathrm{T}}$ (Kalyuzhnaya et al., 2008), and Methylomicrobium pelagicum $\mathrm{AA}-23^{\mathrm{T}}$ (Bowman et al., 1995), are not sequenced, although " $M$. buryatense" has a genome-sequenced representative strain (Figure 2). Despite the lack of genome sequences for these strains, several pieces of evidence suggest that they would also likely belong to Methylotuvimicrobium gen. nov. Firstly, 16S rRNA and PmoA phylogenies consistently placed these species in a monophyletic clade with $M$. alcaliphilum and $M$. kenyense with high bootstrap support (Figure 1 and Supplementary Figure S1; Kalyuzhnaya et al., 2008; Knief, 2015; Bowman, 2016a). Secondly, experimental DDH supports these species to be more closely related to each other and to "M. buryatense" 5G than to M. agile and M. album (Kalyuzhnaya et al., 2008). Thirdly, members of Methylotuvimicrobium gen. nov. are halophilic with most strains also alkaliphilic, which differentiates them from M. agile and M. album (Table 1). Their G+C content range is $48-50 \%$ compared to $52-60 \%$ for Methylomicrobium. Ideally, this reclassification would warrant $M$. pelagicum comb. nov. type species status of the novel genus. However, type strain $\mathrm{AA}-23^{\mathrm{T}}$ has been lost from culture collections, and there are no other cultures available to replace/represent this species (Kalyuzhnaya et al., 2008; Kalyuzhnaya, 2016a). Thus, we also propose $M$. alcaliphilum comb. nov. as the type species of Methylotuvimicrobium gen. nov. since it is the earliest described species with a validly published name after $M$. pelagicum comb. nov. (Kalyuzhnaya et al., 2008). It is imperative to sequence the genomes of the remaining type strains to confirm their placement within this group in the context of a genome phylogeny. Nonetheless, a description of Methylotuvimicrobium gen. nov. and emended descriptions of the species proposed to belong to this genus are included.

Furthermore, the two Methylosarcina type strains, Methylosarcina lacus $\mathrm{LW}^{\mathrm{T}}{ }^{\mathrm{T}}$ and Methylosarcina fibrata $\mathrm{AML}-\mathrm{C} 10^{\mathrm{T}}$, are paraphyletic (Figure 2). This was addressed in the GTDB taxonomy by splitting the two species into separate genera (Parks et al., 2018). However, both strains are monophyletic with M. agile ATCC $35068^{\mathrm{T}}$ and $M$. album $\mathrm{BG} 8^{\mathrm{T}}$, and AAI comparisons between groups (73-82\% AAI) suggest that the two Methylosarcina strains could be reclassified to Methylomicrobium (Supplementary Table S3). However, with M. fibrata as the type species of the genus (Wise et al., 2001), and Methylosarcina quisquiliarum not included in our dataset (i.e., genome is not sequenced), it is premature to completely collapse M. fibrata, M. lacus, and, consequently, M. quisquiliarum with Methylomicrobium without complete genomic information. Based on 16S rRNA phylogeny, $M$. quisquiliarum is more closely related to $M$. fibrata than $M$. lacus (Figure 1A and Supplementary Figure S1A) (Wise et al., 2001; Kalyuzhnaya 
et al., 2005, 2008; Knief, 2015; Bowman, 2016a). Unlike M. fibrata and M. quisquiliarum, M. lacus does not form sarcina-like clusters (Kalyuzhnaya et al., 2005; Kalyuzhnaya, 2016b). The former two species also differ from the latter based on pigmentation (light brown as opposed to white to slightly light cream) and their ability to form cysts (Table 1). The absence of pigmentation and inability to form cysts are shared characteristics between Methylomicrobium and Methylotuvimicrobium gen. nov. In addition, M. lacus was shown previously to be more closely related to M. album than M. fibrata based on whole-genome sequence comparisons (Kalyuzhnaya, 2016b), which is consistent with our findings (Supplementary Table S3). M. lacus is psychrotolerant and is able to grow at lower temperatures $\left(<22^{\circ} \mathrm{C}\right)$, unlike $M$. fibrata and $M$. quisquiliarum (Table 1). M. agile and $M$. album are also capable of growth at temperatures as low as $10^{\circ} \mathrm{C}$. Based on genome phylogeny, genomic comparisons, and phenotypic differences, we propose the reclassification of $M$. lacus into the genus Methylomicrobium as Methylomicrobium lacus comb. nov. Emended descriptions of Methylomicrobium and Methylosarcina are included.

\section{Use of dDDH, ANI, and G+C Content for the Delineation of Species}

Although reclassifications at the genus level has resolved most of the polyphyly and paraphyly within Methylococcales, misclassifications at the species level also need to be addressed. For this, pairwise nucleotide-level comparisons were performed between genome sequences to determine $\mathrm{dDDH}$ (Auch et al., 2010; Meier-Kolthoff et al., 2013) and ANI values (Goris et al., 2007; Figure 4 and Supplementary Table S4). The G+C content from genome sequences was also determined (Supplementary Table S5). Using previously established species delineation standards, two genomes are considered to belong to the same species if they (i) are monophyletic (Rosselló-Móra and Amann, 2001), (ii) have at least $70 \% \mathrm{dDDH}$ (Auch et al., 2010; MeierKolthoff et al., 2013) and 95\% ANI (Goris et al., 2007), and (iii) have less than $1 \%$ difference in $\mathrm{G}+\mathrm{C}$ content (Meier-Kolthoff et al., 2014b). Genomic comparisons revealed 63 species clusters (Figure 2).

Several genomes initially identified as M. tundripaludum proved to be polyphyletic due to the inclusion of unidentified Methylobacter sp. genomes (UBA2091, UBA6696, UBA6701, and UBA6712). dDDH values less than 70\% against type strain SV96 $^{\mathrm{T}}$ (Wartiainen et al., 2006) indicate that none of these genomes can be attributed to $M$. tundripaludum (Supplementary Table S4). Several comparisons within this group, however, showed 95-96\% ANI. In cases where ANI is near the threshold for species delineation (i.e., $94-96 \%$ ), $\mathrm{dDDH}$ is proven to be more discriminatory, as demonstrated with Vibrio cidicii (Orata et al., 2016) and "Bradyrhizobium brasilense" (Martins da Costa et al., 2017), where dDDH values were below the threshold when the species were compared against their closest relatives and ANI was inconclusive. Therefore, the Methylobacter genomes were reclassified into several unidentified species (clusters 1-4 and 6) within a known genus (i.e., Methylobacter) (Figure 2). Several other species clusters with at least two members and identified only up to the genus level include clusters 7 (Methylobacter sp.), 37, 41, 42 (Methylomonas sp.), and 59 (Methylocaldum sp.). It has been shown previously through comparative genomics that the MAGs of species clusters 7 (Methylococcaceae bacterium NSO1 and NSP1-1) and 8 (Methylococcaceae bacterium NSM2-1) are part of the Methylobacter clade (Smith et al., 2018) and strains Kb3 and LW13 (Kalyuzhnaya et al., 2015) of cluster 37 represent a putative novel species of the genus Methylomonas (Rahalkar and Pandit, 2018).

Genus cluster 6 contains the MAGs C. polyspora RSM_CP1 and RSM_CP2 (Figure 2). Since both genomes represent different species (clusters 20 and 21, respectively, based on 26\% dDDH and $80 \%$ ANI) (Supplementary Table S4), only one of the strains can keep the species name. We retained the species designation to strain RSM_CP1 based solely on its phylogenetic affinity with previously sequenced $16 \mathrm{~S}$ rRNA genes from C. polyspora (Oswald et al., 2017).

The four MAGs of species cluster 32 (Methylobacter sp. WM.3.3, DS2.3.46, and DS3.3.25 and Methylomonas sp. FW.017) do not fall within the Methylobacter or Methylomonas clades (Figure 2) but instead represent a different genus and species (92-99\% dDDH and 98-100\% ANI) (Supplementary Table S4). All these MAGs were derived from wastewater metagenomes (Zhang et al., 2017), and a species description cannot be formally proposed until a known isolate of this species is identified (Tindall et al., 2010). These strains are renamed instead as Methylococcaceae bacterium.

Surprisingly, both Methylococcaceae bacterium genomes, TMED282 (species cluster 26) and TMED69 (species cluster 27) (Figure 2), have high $\mathrm{dDDH}$ to other distant MAGs (Figure 4 and Supplementary Table S4). dDDH ranged from 78 to $79 \%$ when TMED282 was compared with genomes UBA659 (species cluster 14) and RSM_CP2 (species cluster 21), and from 78 to $88 \%$ when TMED69 was compared with genomes DS1.3.54, DS1.022 (species cluster 42), and UBA1114 (species cluster 23). In contrast, the same comparisons fell way below the 95\% ANI same-species cut-off (61-63\%). These inferred species clusters contradict the genome phylogeny (i.e., not monophyletic), and the difference in $\mathrm{G}+\mathrm{C}$ content among strains within these clusters is $1-8 \%$ and $4-18 \%$, respectively (Supplementary Table S5), suggesting different species (Rosselló-Móra and Amann, 2001; Meier-Kolthoff et al., 2014b).

\section{Resolving Species-Level Taxonomic Inconsistencies Between Close Relatives}

M. whittenburyi ACM $3310^{\mathrm{T}}$ and UCM-B-3033, M. marinus $\mathrm{A} 45^{\mathrm{T}}$, and Methylobacter sp. BBA5.1 exhibit a relatively high dDDH (88-100\%) and ANI (98-100\%) with each other and should therefore represent the same species (cluster 9) (Figure 2 and Supplementary Table S4). Previous genomic comparisons have also demonstrated that M. whittenburyi ACM $3310^{\mathrm{T}}$ and Methylobacter sp. BBA5.1 have high sequence similarity (99\% ANI) with $M$. marinus $\mathrm{A} 45^{\mathrm{T}}$ (Collins et al., 2017). With the two names appearing in the same publication, priority is determined by page number where the names appear (Rule 24b-2, section 5 of the Bacteriological Code; Lapage et al., 1992). Thus, name priority 


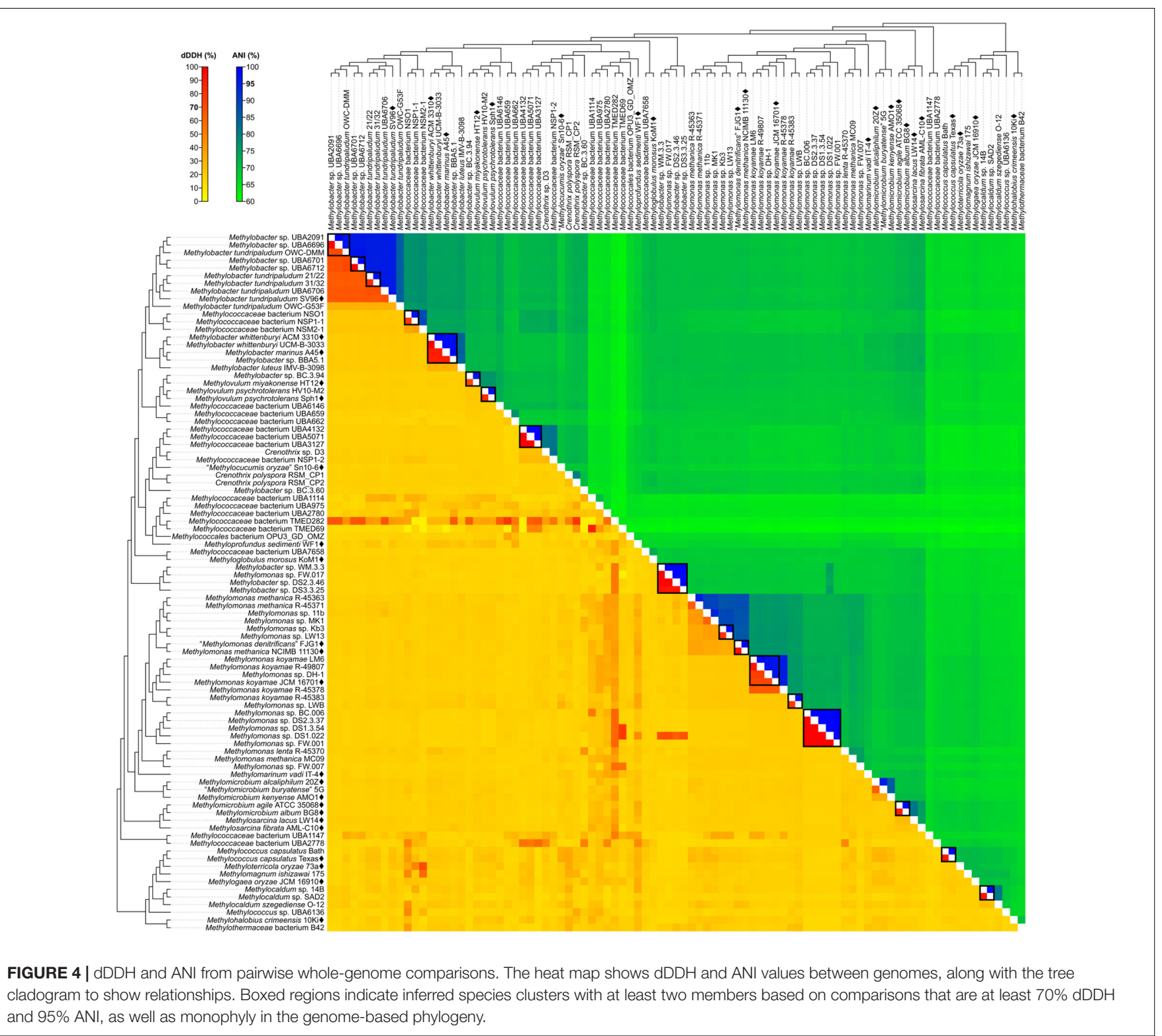

is granted to $M$. marinus over $M$. whittenburyi (Bowman et al., 1993). As such, M. whittenburyi (strain ACM $3310^{\mathrm{T}}$ ) is proposed as a later heterotypic synonym of $M$. marinus (Note 3, Rule 24a, section 5 of the Bacteriological Code; Lapage et al., 1992). Also, UCM-B-3033 and BBA5.1 are identified as Methylobacter marinus. An emended description of M. marinus is included.

Comparisons between $M$. agile ATCC $35068^{\mathrm{T}}$ and M. album $\mathrm{BG}^{\mathrm{T}}$ resulted in $90 \% \mathrm{dDDH}$ and 99\% ANI (Supplementary Table S4), and both strains should represent the same species (cluster 50) (Figure 2). This high ANI was also shown in a previous work (Kalyuzhnaya, 2016a). With M. agile, being the type species of the genus and described before M. album (Bowman et al., 1995), the former species should take name priority over M. album (Rule 23a, section 5 and Rule 38, section 7 of the Bacteriological Code; Lapage et al., 1992); thus, M. album is presumed to be a later heterotypic synonym. However, there is circumstantial evidence of misidentification of the currently deposited ATCC (American Type Culture Collection) strains for both species. Preliminary data suggests that strain ATCC $35068^{\mathrm{T}}$ (M. agile) is phenotypically similar to M. album, whereas strain ATCC $33003^{\mathrm{T}}$ (M. album) is similar to Methylosinus sporium (Dr. M. G. Kalyuzhnaya, personal communication). It is possible that the strains were interchanged, mislabeled, or lost, and that the M. agile ATCC $35068^{\mathrm{T}}$ genome sequence was from an $M$. album isolate. Tracking the original M. agile and $M$. album isolates is difficult since they were originally isolated and identified in 1970 (as Methylomonas agile and Methylomonas albus, respectively) (Whittenbury et al., 1970). Also, it is unfortunately common for methanotrophic isolates to be lost from or mis-deposited into culture collections, as these isolates take substantial efforts to maintain (Bowman, 2016b). Both strains are no longer available from the NCIMB 
(National Collection of Industrial Food and Marine Bacteria), where the strains were also initially deposited (Bowman et al., 1993, 1995). This matter requires further investigation, with the need to track laboratories that would have maintained stocks of both strains to perform extensive phenotypic characterizations and to re-sequence the genomes to confirm their identities, as well as to replace or deposit the strains in multiple culture collections.

It was suggested that members of the newly proposed Methylotuvimicrobium gen. nov., M. alcaliphilum comb. nov. $20 \mathrm{Z}^{\mathrm{T}}$ and " $M$. buryatense" comb. nov. 5G, be considered a single species based on 95\% ANI (Kalyuzhnaya, 2016a). While we obtained a similar borderline ANI value, $\mathrm{dDDH}$ is only $63 \%$, providing a much stronger argument to maintain the two as different species (clusters 47 and 48, respectively) (Figure 2 and Supplementary Table S4). They can be distinguished from each other since "M. buryatense" comb. nov., unlike M. alcaliphilum comb. nov., is able to grow at $45^{\circ} \mathrm{C}$ and contains a soluble methane monooxygenase (sMMO) (Table 1).

Genomic comparisons also revealed misclassifications of some Methylomonas strains. Type strains M. methanica NCIMB $11130^{\mathrm{T}}$ and " $M$. denitrificans" $\mathrm{FJG} \mathrm{1}^{\mathrm{T}}$ exhibit $92 \% \mathrm{dDDH}$ and $100 \%$ ANI with each other, indicating that they should be considered as the same species (cluster 38) (Figure 2 and Supplementary Table S4). Both strains are pale pink, utilize flagella for motility, and are neutrophilic and mesophilic, which are characteristics of $M$. methanica (Kits et al., 2015; Bowman, 2016b). With "M. denitrificans" being described much later than M. methanica, the former name is proposed to be a later heterotypic synonym of the latter. Moreover, strains R-45363, R-45371, and MC09 (species clusters 33, 34, and 44 , respectively), currently identified as M. methanica (Boden

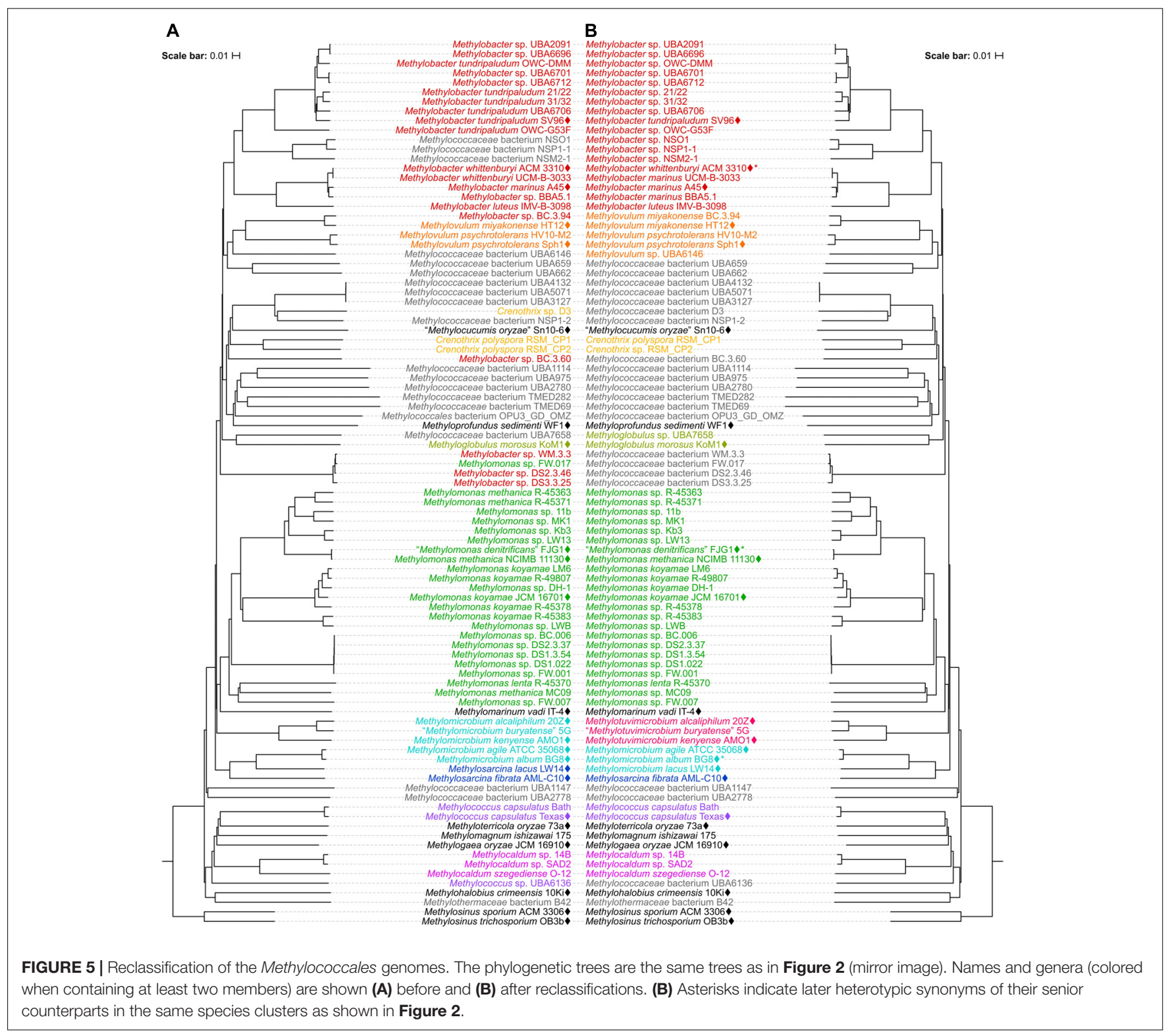


et al., 2011; Heylen et al., 2016), do not belong to this species since they are not monophyletic with the $M$. methanica strains (Figure 2) and genomic comparisons revealed only 21-35\% dDDH and 74-88\% ANI (Supplementary Table S4). Additionally, sMMO is predicted to be absent in M. methanica (Heylen et al., 2016; Orata et al., 2018) but present in R-45363, R-45371, and MC09 (Boden et al., 2011; Heylen et al., 2016). Methylomonas lenta R-45370 (species cluster 43) (Hoefman et al., 2014; Heylen et al., 2016) is the closest known relative of strain MC09 (Figure 2), but they do not represent the same species (21\% dDDH and 76\% ANI) (Supplementary Table S4). Therefore, these three strains are renamed as Methylomonas sp. and each represent a putative novel species. They need to be extensively characterized phenotypically in comparison to their closest relatives to justify their classification into novel species.

\section{Incorporating Whole-Genome Sequencing to Prokaryotic Taxonomy: Advantages and Limitations}

The results from reclassifications are summarized in Figure 5 and Supplementary Table S5. For the sake of consistency and accuracy of the analyses, the reclassifications in this study were mainly limited to strains with available genome sequences. The genomes of the majority of Methylococcales type strains have yet to be sequenced. In fact, only 22 out of the 49 currently identified type strains (including those with effectively but not validly published names) have sequenced genomes (Figure 2). Nonetheless, we considered exceptions for some type strains that are not genome-sequenced, for currently available information (i.e., highly supported clades in both 16S rRNA and PmoA phylogenies, experimental DDH, phenotypic similarities, etc.) are sufficient to support our proposed reclassifications. Incorporation of genome sequence data is not mandatory in officially describing a novel taxon (Tindall et al., 2010), however, the routine description of species on the basis of their genome sequences is recommended, which would allow for type strains to be uniquely and unambiguously identified to avoid redundancies and inconsistencies in taxonomy (Whitman, 2011; Thompson et al., 2015; Chun et al., 2018). Additionally, since the current taxonomic practice is highly reliant on comparisons with type strains (Tindall et al., 2010), this also becomes a limitation (Konstantinidis et al., 2017). Several genomes in our dataset were binned from metagenomes obtained from various methane sinks (Skennerton et al., 2015; Oswald et al., 2017; Parks et al., 2017; Zhang et al., 2017; Smith et al., 2018) that currently do not show any affinity with sequenced type strains and therefore cannot be officially designated species names.

It is still recommended that a genomic approach to descriptions of novel taxa must not abandon the fundamental principles of taxonomy, which includes the incorporation of phenotypic data (Tindall et al., 2010; Kämpfer and Glaeser, 2012; Garrity, 2016). Our reclassifications incorporated phenotypic characterizations when needed (e.g., between Methylotuvimicrobium gen. nov., Methylomicrobium, and Methylosarcina) (Table 1). However, phenotypic characterizations should be genome phylogeny-guided, not the reverse (Hahnke et al., 2016; Nouioui et al., 2018). Inconsistencies between single-gene phylogenies (e.g., 16S rRNA and PmoA) and instances of poly- and paraphyly within Methylococcales have generally been overlooked in the past in favor of phenotypic similarities (Bowman, 2016a, 2018). Regardless of phenotype, inclusion of an isolate to a known or novel taxon should first and foremost be supported by genome phylogeny (i.e., highly supported monophyletic clade) and supplemented with whole-genome comparisons (i.e., $\mathrm{AAI}, \mathrm{dDDH}$, and $\mathrm{ANI}$ ) so that extensive poly- and paraphyly do not confuse taxonomy and subsequent interpretation.

\section{CONCLUSION}

Our work successfully established a whole-genome-based phylogeny for all currently available Methylococcales genome sequences. In addition, pairwise genome comparisons were used to supplement the robust phylogeny to confidently reclassify several previously identified genomes, as well as provide identities to some unidentified genomes, including MAGs. This work serves as a foundation for the classification/reclassification of current and future isolates within Methylococcales. This approach will enable consistent and reliable classification of Methyloccocales, which becomes more and more important as the number of isolated and sequenced strains is rapidly growing.

\section{TAXONOMIC RECLASSIFICATIONS}

\section{Description of Methylotuvimicrobium gen. nov.}

Me.thy.lo.tu.vi.mi.cro'bi.um. N.L. n. methylum (from French méthyle, back-formation from French méthylène, coined from Gr. n. methu, wine and Gr. n. hulê, wood), the methyl radical; N.L. pref. methylo-, pertaining to the methyl radical; N.L. neut. adj. tuvi, pertaining to Tuva, Russia, the isolation source of the type species and strain; N.L. neut. n. microbium (from Gr. adj. mikros, small, and Gr. n. bios, life), microbe; N.L. neut. n. Methylotuvimicrobium, methane-utilizing microbe first isolated from Tuva, Russia.

Cells are Gram-negative and mainly rods but can also vary to ellipsoids, ovoids, and coccoids. $0.5-1.5 \mu \mathrm{m} \times 0.8-3.0 \mu \mathrm{m}$ in size. Reproduce by binary fission. Motile mainly by a single polar flagellum but some may possess up to three peritrichous flagella. Stacks of intracytoplasmic membrane present. Do not form cysts. Colonies are white to slightly cream. Grow in a wide range of $\mathrm{pH}$ from 6 to 11 , temperature from 4 to $45^{\circ} \mathrm{C}$, and salinity from 0.03 to $1.5 \mathrm{M} \mathrm{NaCl}$, with varying optimal conditions per species. Some species are resistant to desiccation and heat $\left(80^{\circ} \mathrm{C}\right)$. Some species possess an sMMO. The most abundant fatty acids are $C_{16: 1}, C_{16: 1} \omega 7 c$, or $C_{16: 1}$ $\omega 5 \mathrm{t}$, with type depending on the species. DNA $\mathrm{G}+\mathrm{C}$ content from 48 to $50.2 \mathrm{~mol} \%$. The type species for the genus is Methylotuvimicrobium alcaliphilum. 


\section{Description of Methylotuvimicrobium alcaliphilum, comb. nov.}

Basonym: Methylomicrobium alcaliphilum (Kalyuzhnaya et al., 2008). The description is the same as that of the genus and for Methylomicrobium alcaliphilum (Kalyuzhnaya et al., 2008) with the following amendment. DNA G+C content of type strain $20 \mathrm{Z}^{\mathrm{T}}$ $\left(=\right.$ VKM B- $2133^{\mathrm{T}}=$ NCIMB $\left.14124^{\mathrm{T}}=\mathrm{DSM} 19304^{\mathrm{T}}\right)$ is $48.7 \mathrm{~mol} \%$ based on its whole-genome sequence.

\section{Description of "Methylotuvimicrobium buryatense," comb. nov.}

Basonym: "Methylomicrobium buryatense" (Kaluzhnaya et al., 2001). The description is the same as that of the genus and for "Methylomicrobium buryatense" (Kaluzhnaya et al., 2001) with the following amendment. DNA G+C content of strain $5 \mathrm{G}$ is $48.7 \mathrm{~mol} \%$ based on its whole-genome sequence.

\section{Description of Methylotuvimicrobium kenyense, comb. nov.}

Basonym: Methylomicrobium kenyense (Kalyuzhnaya et al., 2008). The description is the same as that of the genus and for Methylomicrobium kenyense (Kalyuzhnaya et al., 2008) with the following amendment. DNA G+C content of type strain $\mathrm{AMO}^{\mathrm{T}}\left(=\mathrm{NCCB} 97157^{\mathrm{T}}=\mathrm{VKM} \mathrm{B}-2464^{\mathrm{T}}=\mathrm{NCIMB}\right.$ $13566^{\mathrm{T}}=\mathrm{DSM} 19305^{\mathrm{T}}$ ) is $50.2 \mathrm{~mol} \%$ based on its whole-genome sequence.

\section{Description of Methylotuvimicrobium japanense, comb. nov.}

Basonym: Methylomicrobium japanense (Kalyuzhnaya et al., 2008). The description is the same as that of the genus and for Methylomicrobium japanense (Kalyuzhnaya et al., 2008). Despite the absence of a genome-sequenced representative strain, $16 S$ rRNA and PmoA phylogenies, phenotypic characteristics, and experimental DDH provided strong evidence for the placement of this species in the genus Methylotuvimicrobium gen. nov.

\section{Description of Methylotuvimicrobium pelagicum, comb. nov.}

Basonym: Methylomicrobium pelagicum (Sieburth et al., 1987; Bowman et al., 1995). The description is the same as that of the genus and for Methylomicrobium pelagicum (Bowman et al., 1993, 1995). Despite the absence of a genome-sequenced representative strain, 16S rRNA phylogeny, phenotypic characteristics, and experimental DDH provided strong evidence for the placement of this species in the genus Methylotuvimicrobium gen. nov.

\section{Description of Methylomicrobium lacus, comb. nov.}

Basonym: Methylosarcina lacus (Kalyuzhnaya et al., 2005). The description is the same as for Methylosarcina lacus (Kalyuzhnaya et al., 2005) with the following amendment. DNA G+C content of type strain $\mathrm{LW} 14^{\mathrm{T}}\left(=\right.$ ATCC BAA- $\left.1047^{\mathrm{T}}=\mathrm{JCM} 13284^{\mathrm{T}}\right)$ is $54.7 \mathrm{~mol} \%$ based on its whole-genome sequence.

\section{Emended Description of Methylomicrobium (Bowman et al., 1995) emend. (Kalyuzhnaya et al., 2008)}

The description is the same as given by Bowman et al. (1995) and Kalyuzhnaya et al. (2008) with the following amendments. Cells are short rods or coccobacilli. $0.5-1.0 \mu \mathrm{m} \times 1.0-2.5 \mu \mathrm{m}$ in size. Cells may be motile by means of a single polar flagellum or nonmotile. Mostly mesophilic, with optimum temperature for growth at $25-30^{\circ} \mathrm{C}$; range, $4-37^{\circ} \mathrm{C}$. Optimum $\mathrm{pH}$ for growth from 5.5 to 7; range, $\mathrm{pH} 4-9$. All species possess a $\mathrm{pMMO}$ but no sMMO. The most abundant fatty acids are $\mathrm{C}_{16: 1} \omega 5$ t or $\mathrm{C}_{16: 1} \omega 8 \mathrm{c}$, with type depending on the species. DNA G+C content from 52 to $59.6 \mathrm{~mol} \%$.

\section{Emended Description of Methylosarcina (Wise et al., 2001) emend. (Kalyuzhnaya et al., 2005)}

The description is the same as given by Wise et al. (2001) and excludes the amendments by Kalyuzhnaya et al. (2005) due to the proposed transference of Methylosarcina lacus (Kalyuzhnaya et al., 2005) to the genus Methylomicrobium (Bowman et al., 1995) emend. (Kalyuzhnaya et al., 2008).

\section{Emended Description of Methylobacter marinus (Bowman et al., 1993)}

The description is the same as given by Bowman et al. (1993) with the following amendments. Cells are $0.8-1.5 \mu \mathrm{m} \times 1.5-$ $3.0 \mu \mathrm{m}$. May or may not require $\mathrm{NaCl}$ for growth. Optimum temperature for growth, $\sim 30-35^{\circ} \mathrm{C}$; range, $15-40^{\circ} \mathrm{C}$. DNA G+C content from 48.7 to $53.7 \mathrm{~mol} \%$. DNA G+C content of type strain $\mathrm{A} 45^{\mathrm{T}}\left(=\right.$ Lidstrom $\mathrm{A} 4^{\mathrm{T}}=\mathrm{ACM} 4717^{\mathrm{T}}$ ) is $52.7 \mathrm{~mol} \%$ based on its whole-genome sequence.

\section{AUTHOR CONTRIBUTIONS}

FO, DS, and LS conceived and supervised the work. FO and JM-K carried out the phylogenetic and comparative genomic analyses. FO drafted the original manuscript. All authors reviewed and approved the manuscript.

\section{FUNDING}

This work was supported by funding from the Future Energy Systems Research Initiative of the University of Alberta to FO, DS, and LS, a Discovery Grant from the Natural Sciences and Engineering Research Council to LS, and the Deutsche Forschungsgemeinschaft (TRR 51) to JM-K. The funders had no role in study design, data collection and analysis, decision to publish, or preparation of the manuscript. 


\section{ACKNOWLEDGMENTS}

We would like to thank Dr. Marina Kalyuzhnaya (San Diego State University) and Dr. Ludmila Chistoserdova (University of Washington) for the helpful discussions.

\section{REFERENCES}

Ad Hoc Committee of the Judicial Commission of the ICSB (1989). Approved Lists of Bacterial Names (Amended). Washington, DC: ASM Press.

Aliyu, H., Lebre, P., Blom, J., Cowan, D., and De Maayer, P. (2016). Phylogenomic re-assessment of the thermophilic genus Geobacillus. Syst. Appl. Microbiol. 39, 527-533. doi: 10.1016/j.syapm.2016.09.004

Auch, A. F., von Jan, M., Klenk, H. P., and Göker, M. (2010). Digital DNA-DNA hybridization for microbial species delineation by means of genome-to-genome sequence comparison. Stand. Genomic Sci. 2, 117-134. doi: 10.4056/sigs.531120

Benson, D. A., Cavanaugh, M., Clark, K., Karsch-Mizrachi, I., Ostell, J., Pruitt, K. D., et al. (2018). GenBank. Nucleic Acids Res. 46, D41-D47. doi: 10.1093/ nar/gkx1094

Boden, R., Cunliffe, M., Scanlan, J., Moussard, H., Kits, K. D., Klotz, M. G., et al. (2011). Complete genome sequence of the aerobic marine methanotroph Methylomonas methanica MC09. J. Bacteriol. 193, 7001-7002. doi: 10.1128/JB. 06267-11

Bowman, J. P. (2016a). "Methylococcaceae," in Bergey's Manual of Systematics of Archaea and Bacteria, eds W. B. Whitman, F. Rainey, P. Kämpfer, M. Trujillo, J. Chun, P. De Vos, et al. (Hoboken, NJ: John Wiley \& Sons, Inc).

Bowman, J. P. (2016b). "Methylomonas," in Bergey's Manual of Systematics of Archaea and Bacteria, eds W. B. Whitman, F. Rainey, P. Kämpfer, M. Trujillo, J. Chun, P. De Vos, et al. (Hoboken, NJ: John Wiley \& Sons, Inc).

Bowman, J. P. (2018). "Methylococcales," in Bergey's Manual of Systematics of Archaea and Bacteria, eds W. B. Whitman, F. Rainey, P. Kämpfer, M. Trujillo, J. Chun, P. De Vos, et al. (Hoboken, NJ: John Wiley \& Sons, Inc).

Bowman, J. P., Sly, L. I., Nichols, P. D., and Hayward, A. C. (1993). Revised taxonomy of the methanotrophs: description of Methylobacter gen. nov., emendation of Methylococcus, validation of Methylosinus and Methylocystis species, and a proposal that the family Methylococcaceae includes only the group I methanotrophs. Int. J. Syst. Evol. Microbiol. 43, 735-753.

Bowman, J. P., Sly, L. I., and Stackebrandt, E. (1995). The phylogenetic position of the family Methylococcaceae. Int. J. Syst. Bacteriol. 45, 182-185. doi: 10.1099/ 00207713-45-1-182

Buchfink, B., Xie, C., and Huson, D. H. (2015). Fast and sensitive protein alignment using DIAMOND. Nat. Methods 12, 59-60. doi: 10.1038/nmeth.3176

Camacho, C., Coulouris, G., Avagyan, V., Ma, N., Papadopoulos, J., Bealer, K., et al. (2009). BLAST+: architecture and applications. BMC Bioinformatics 10:421. doi: 10.1186/1471-2105-10-421

Castresana, J. (2000). Selection of conserved blocks from multiple alignments for their use in phylogenetic analysis. Mol. Biol. Evol. 17, 540-552. doi: 10.1093/ oxfordjournals.molbev.a026334

Chun, J., Oren, A., Ventosa, A., Christensen, H., Arahal, D. R., da Costa, M. S., et al. (2018). Proposed minimal standards for the use of genome data for the taxonomy of prokaryotes. Int. J. Syst. Evol. Microbiol. 68, 461-466. doi: 10.1099/ijsem.0.002516

Chun, J., and Rainey, F. A. (2014). Integrating genomics into the taxonomy and systematics of the Bacteria and Archaea. Int. J. Syst. Evol. Microbiol. 64, 316-324. doi: $10.1099 /$ ijs.0.054171-0

Cicerone, R. J., and Oremland, R. S. (1988). Biogeochemical aspects of atmospheric methane. Glob. Biogeochem. Cycles 2, 299-327. doi: 10.1029/GB002i004p00299

Collins, D. A., Akberdin, I. R., and Kalyuzhnaya, M. G. (2017). "Methylobacter," in Bergey's Manual of Systematics of Archaea and Bacteria, eds W. B. Whitman, F. Rainey, P. Kämpfer, M. Trujillo, J. Chun, P. De Vos, et al. (Hoboken, NJ: John Wiley \& Sons, Inc).

Dyksterhouse, S. E., Gray, J. P., Herwig, R. P., Lara, J. C., and Staley, J. T. (1995). Cycloclasticus pugetii gen. nov., sp. nov., an aromatic hydrocarbondegrading bacterium from marine sediments. Int. J. Syst. Bacteriol. 45, 116-123. doi: 10.1099/00207713-45-1-116

\section{SUPPLEMENTARY MATERIAL}

The Supplementary Material for this article can be found online at: https://www.frontiersin.org/articles/10.3389/fmicb. 2018.03162/full\#supplementary-material

Edenhofer, O., Pichs-Madruga, R., Sokona, Y., Kadner, S., Minx, J. C., Brunner, S., et al. (2014). "IPCC, 2014: technical summary," in Climate Change 2014 Mitigation of Climate Change. Contribution of Working Group III to the Fifth Assessment Report of the Intergovernmental Panel on Climate Change, eds $\mathrm{O}$. Edenhofer, R. Pichs-Madruga, Y. Sokona, E. Farahani, S. Kadner, K. Seyboth, et al. (Cambridge: Cambridge University Press), 33-107.

Foster, J. W., and Davis, R. H. (1966). A methane-dependent coccus, with notes on classification and nomenclature of obligate, methane-utilizing bacteria. J. Bacteriol. 91, 1924-1931.

Frindte, K., Maarastawi, S. A., Lipski, A., Hamacher, J., and Knief, C. (2017). Characterization of the first rice paddy cluster I isolate, Methyloterricola oryzae gen. nov., sp. nov. and amended description of Methylomagnum ishizawai. Int. J. Syst. Evol. Microbiol. 67, 4507-4514. doi: 10.1099/ijsem.0.002319

Garrity, G. M. (2016). A new genomics-driven taxonomy of Bacteria and Archaea: are we there yet? J. Clin. Microbiol. 54, 1956-1963. doi: 10.1128/JCM. 00200-16

Geiselbrecht, A. D. (2015). "Cycloclasticus," in Bergey's Manual of Systematics of Archaea and Bacteria, eds W. B. Whitman, F. Rainey, P. Kämpfer, M. Trujillo, J. Chun, P. De Vos, et al. (Hoboken, NJ: John Wiley \& Sons, Inc).

Goris, J., Konstantinidis, K. T., Klappenbach, J. A., Coenye, T., Vandamme, P., and Tiedje, J. M. (2007). DNA-DNA hybridization values and their relationship to whole-genome sequence similarities. Int. J. Syst. Evol. Microbiol. 57, 81-91. doi: 10.1099/ijs.0.64483-0

Hahnke, R. L., Meier-Kolthoff, J. P., García-López, M., Mukherjee, S., Huntemann, M., Ivanova, N. N., et al. (2016). Genome-based taxonomic classification of Bacteroidetes. Front. Microbiol. 7:2003. doi: 10.3389/fmicb.2016. 02003

Hanson, R. S., and Hanson, T. E. (1996). Methanotrophic bacteria. Microbiol. Rev. 60, 439-471.

Henz, S. R., Huson, D. H., Auch, A. F., Nieselt-Struwe, K., and Schuster, S. C. (2005). Whole-genome prokaryotic phylogeny. Bioinformatics 21, 2329-2335. doi: 10.1093/bioinformatics/bth324

Heyer, J., Berger, U., Hardt, M., and Dunfield, P. F. (2005). Methylohalobius crimeensis gen. nov., sp. nov., a moderately halophilic, methanotrophic bacterium isolated from hypersaline lakes of Crimea. Int. J. Syst. Evol. Microbiol. 55, 1817-1826. doi: 10.1099/ijs.0.63213-0

Heylen, K., De Vos, P., and Vekeman, B. (2016). Draft genome sequences of eight obligate methane oxidizers occupying distinct niches based on their nitrogen metabolism. Genome Announc. 4:e00421-16. doi: 10.1128/genomeA.00421-16

Hirayama, H. (2016). "Methylothermaceae," in Bergey's Manual of Systematics of Archaea and Bacteria, eds W. B. Whitman, F. Rainey, P. Kämpfer, M. Trujillo, J. Chun, P. De Vos, et al. (Hoboken, NJ: John Wiley \& Sons, Inc).

Hirayama, H., Abe, M., Miyazaki, M., Nunoura, T., Furushima, Y., Yamamoto, H., et al. (2014). Methylomarinovum caldicuralii gen. nov., sp. nov., a moderately thermophilic methanotroph isolated from a shallow submarine hydrothermal system, and proposal of the family Methylothermaceae fam. nov. Int. J. Syst. Evol. Microbiol. 64, 989-999. doi: 10.1099/ijs.0.058172-0

Hodcroft, E. (2016). TreeCollapserCL 4. Available at: http://emmahodcroft.com/ TreeCollapseCL.html [accessed September 27, 2018].

Hoefman, S., Heylen, K., and De Vos, P. (2014). Methylomonas lenta sp. nov., a methanotroph isolated from manure and a denitrification tank. Int. J. Syst. Evol. Microbiol. 64, 1210-1217. doi: 10.1099/ijs.0.057794-0

Hyatt, D., Chen, G. L., LoCascio, P. F., Land, M. L., Larimer, F. W., and Hauser, L. J. (2010). Prodigal: prokaryotic gene recognition and translation initiation site identification. BMC Bioinformatics 11:119. doi: 10.1186/1471-210511-119

Iguchi, H., Yurimoto, H., and Sakai, Y. (2011). Methylovulum miyakonense gen. nov., sp. nov., a Type I methanotroph isolated from forest soil. Int. J. Syst. Evol. Microbiol. 61, 810-815. doi: 10.1099/ijs.0.019604-0 
Kaluzhnaya, M., Khmelenina, V., Eshinimaev, B., Suzina, N., Nikitin, D., Solonin, A., et al. (2001). Taxonomic characterization of new alkaliphilic and alkalitolerant methanotrophs from soda lakes of the Southeastern Transbaikal region and description of Methylomicrobium buryatense sp. nov. Syst. Appl. Microbiol. 24, 166-176. doi: 10.1078/0723-2020-00028

Kalyuzhnaya, M. G. (2016a). "Methylomicrobium," in Bergey's Manual of Systematics of Archaea and Bacteria, eds W. B. Whitman, F. Rainey, P. Kämpfer, M. Trujillo, J. Chun, P. De Vos, et al. (Hoboken, NJ: John Wiley \& Sons, Inc).

Kalyuzhnaya, M. G. (2016b). "Methylosarcina," in Bergey's Manual of Systematics of Archaee and Bacteria, eds W. B. Whitman, F. Rainey, P. Kämpfer, M. Trujillo, J. Chun, P. De Vos, et al. (Hoboken, NJ: John Wiley \& Sons, Inc).

Kalyuzhnaya, M. G., Khmelenina, V., Eshinimaev, B., Sorokin, D., Fuse, H., Lidstrom, M., et al. (2008). Classification of halo(alkali)philic and halo(alkali)tolerant methanotrophs provisionally assigned to the genera Methylomicrobium and Methylobacter and emended description of the genus Methylomicrobium. Int. J. Syst. Evol. Microbiol. 58, 591-596. doi: 10.1099/ijs.0.65317-0

Kalyuzhnaya, M. G., Lamb, A. E., McTaggart, T. L., Oshkin, I. Y., Shapiro, N., Woyke, T., et al. (2015). Draft genome sequences of gammaproteobacterial methanotrophs isolated from Lake Washington sediment. Genome Announc. 3:e00103-15. doi: 10.1128/genomeA.00103-15

Kalyuzhnaya, M. G., Stolyar, S. M., Auman, A. J., Lara, J. C., Lidstrom, M. E., and Chistoserdova, L. (2005). Methylosarcina lacus sp. nov., a methanotroph from Lake Washington, Seattle, USA, and emended description of the genus Methylosarcina. Int. J. Syst. Evol. Microbiol. 55, 2345-2350. doi: 10.1099/ijs.0. 63405-0

Kalyuzhnaya, M. G., and Xing, X. H. (2018). Methane Biocatalysis: Paving the Way to Sustainability. Cham: Springer.

Kämpfer, P., and Glaeser, S. P. (2012). Prokaryotic taxonomy in the sequencing era - the polyphasic approach revisited. Environ. Microbiol. 14, 291-317. doi: 10.1111/j.1462-2920.2011.02615.x

Katoh, K., and Standley, D. M. (2013). MAFFT multiple sequence alignment software version 7: improvements in performance and usability. Mol. Biol. Evol. 30, 772-780. doi: 10.1093/molbev/mst010

Kearse, M., Moir, R., Wilson, A., Stones-Havas, S., Cheung, M., Sturrock, S., et al. (2012). Geneious Basic: an integrated and extendable desktop software platform for the organization and analysis of sequence data. Bioinformatics 28, 1647-1649. doi: 10.1093/bioinformatics/bts199

Kits, K. D., Klotz, M. G., and Stein, L. Y. (2015). Methane oxidation coupled to nitrate reduction under hypoxia by the gammaproteobacterium Methylomonas denitrificans, sp. nov. type strain FJG1. Environ. Microbiol. 17, 3219-3232. doi: $10.1111 / 1462-2920.12772$

Knief, C. (2015). Diversity and habitat preferences of cultivated and uncultivated aerobic methanotrophic bacteria evaluated based on $p m o A$ as molecular marker. Front. Microbiol. 6:1346. doi: 10.3389/fmicb.2015.01346

Konstantinidis, K. T., Rosselló-Móra, R., and Amann, R. (2017). Uncultivated microbes in need of their own taxonomy. ISME J. 11, 2399-2406. doi: 10.1038/ ismej.2017.113

Konstantinidis, K. T., and Tiedje, J. M. (2005). Towards a genome-based taxonomy for prokaryotes. J. Bacteriol. 187, 6258-6264. doi: 10.1128/JB.187.18.6258-6264. 2005

Kyrpides, N. C., Hugenholtz, P., Eisen, J. A., Woyke, T., Göker, M., Parker, C. T., et al. (2014). Genomic encyclopedia of Bacteria and Archaea: sequencing a myriad of type strains. PLoS Biol. 12:e1001920. doi: 10.1371/journal.pbio. 1001920

Lapage, S. P., Sneath, P. H. A., Lessel, E. F., Skerman, V. B. D., Seeliger, H. P. R., and Clark, W. A. (1992). "Chapter 3: rules of nomenclature with recommendations," in International Code of Nomenclature of Bacteria: Bacteriological Code, 1990 Revision, eds S. P. Lapage, P. H. A. Sneath, E. F. Lessel, V. B. D. Skerman, H. P. R. Seeliger, and W. A. Clark (Washington, DC: ASM Press).

Lefort, V., Desper, R., and Gascuel, O. (2015). FastME 2.0: a comprehensive, accurate, and fast distance-based phylogeny inference program. Mol. Biol. Evol. 32, 2798-2800. doi: 10.1093/molbev/msv150

Letunic, I., and Bork, P. (2016). Interactive tree of life (iTOL) v3: an online tool for the display and annotation of phylogenetic and other trees. Nucleic Acids Res. 44, W242-W245. doi: 10.1093/nar/gkw290

Li, Y., Xue, H., Sang, S. Q., Lin, C. L., and Wang, X. Z. (2017). Phylogenetic analysis of family Neisseriaceae based on genome sequences and description of
Populibacter corticis gen. nov., sp. nov., a member of the family Neisseriaceae, isolated from symptomatic bark of Populus $\times$ euramericana canker. PLoS One 12:e0174506. doi: 10.1371/journal.pone.0174506

Lopes-Santos, L., Castro, D. B. A., Ferreira-Tonin, M., Corrêa, D. B. A., Weir, B. S., Park, D., et al. (2017). Reassessment of the taxonomic position of Burkholderia andropogonis and description of Robbsia andropogonis gen. nov., comb. nov. Antonie Van Leeuwenhoek 110, 727-736. doi: 10.1007/s10482-0170842-6

Luo, C., Rodriguez-R, L. M., and Konstantinidis, K. T. (2014). MyTaxa: an advanced taxonomic classifier for genomic and metagenomic sequences. Nucleic Acids Res. 42, e73. doi: 10.1093/nar/gku169

Martins da Costa, E., Azarias Guimaraes, A., Pereira Vicentin, R., de Almeida Ribeiro, P. R., Ribas Leao, A. C., et al. (2017). Bradyrhizobium brasilense sp. nov., a symbiotic nitrogen-fixing bacterium isolated from Brazilian tropical soils. Arch. Microbiol. 199, 1211-1221. doi: 10.1007/s00203-017-1390-1

Mateos-Rivera, A., Islam, T., Marshall, I. P. G., Schreiber, L., and Øvreås, L. (2018). High-quality draft genome of the methanotroph Methylovulum psychrotolerans str. HV10-M2 isolated from plant material at a high-altitude environment. Stand. Genomic Sci. 13:10. doi: 10.1186/s40793-018-0314-2

Médigue, C., Calteau, A., Cruveiller, S., Gachet, M., Gautreau, G., Josso, A., et al. (2017). MicroScope-an integrated resource for community expertise of gene functions and comparative analysis of microbial genomic and metabolic data. Brief. Bioinform. doi: 10.1093/bib/bbx113 [Epub ahead of print].

Meier-Kolthoff, J. P., Auch, A. F., Klenk, H. P., and Göker, M. (2013). Genome sequence-based species delimitation with confidence intervals and improved distance functions. BMC Bioinformatics 14:60. doi: 10.1186/1471-2105-14-60

Meier-Kolthoff, J. P., Auch, A. F., Klenk, H. P., and Göker, M. (2014a). Highly parallelized inference of large genome-based phylogenies. Concurr. Comput. Pract. Exp. 26, 1715-1729. doi: 10.1002/cpe.3112

Meier-Kolthoff, J. P., Klenk, H. P., and Göker, M. (2014b). Taxonomic use of DNA $\mathrm{G}+\mathrm{C}$ content and DNA-DNA hybridization in the genomic age. Int. J. Syst. Evol. Microbiol. 64, 352-356. doi: 10.1099/ijs.0.056994-0

Mukherjee, S., Seshadri, R., Varghese, N. J., Eloe-Fadrosh, E. A., Meier-Kolthoff, J. P., Göker, M., et al. (2017). 1,003 reference genomes of bacterial and archaeal isolates expand coverage of the tree of life. Nat. Biotechnol. 35, 676-683. doi: $10.1038 /$ nbt.3886

Nouioui, I., Carro, L., Garcia-Lopez, M., Meier-Kolthoff, J. P., Woyke, T., Kyrpides, N. C., et al. (2018). Genome-based taxonomic classification of the phylum Actinobacteria. Front. Microbiol. 9:2007. doi: 10.3389/fmicb.2018. 02007

Ogiso, T., Ueno, C., Dianou, D., Huy, T. V., Katayama, A., Kimura, M., et al. (2012). Methylomonas koyamae sp. nov., a Type I methane-oxidizing bacterium from floodwater of a rice paddy field. Int. J. Syst. Evol. Microbiol. 62, 1832-1837. doi: 10.1099/ijs.0.035261-0

Orata, F. D., Kits, K. D., and Stein, L. Y. (2018). Complete genome sequence of Methylomonas denitrificans strain FJG1, an obligate aerobic methanotroph that can couple methane oxidation with denitrification. Genome Announc. 6:e00276-18. doi: 10.1128/genomeA.00276-18

Orata, F. D., Xu, Y., Gladney, L. M., Rishishwar, L., Case, R. J., Boucher, Y., et al. (2016). Characterization of clinical and environmental isolates of Vibrio cidicii sp. nov., a close relative of Vibrio navarrensis. Int. J. Syst. Evol. Microbiol. 66, 4148-4155. doi: 10.1099/ijsem.0.001327

Oshkin, I. Y., Belova, S. E., Danilova, O. V., Miroshnikov, K. K., Rijpstra, W. I., Sinninghe Damste, J. S., et al. (2016). Methylovulum psychrotolerans sp. nov., a cold-adapted methanotroph from low-temperature terrestrial environments, and emended description of the genus Methylovulum. Int. J. Syst. Evol. Microbiol. 66, 2417-2423. doi: 10.1099/ijsem.0.001046

Oswald, K., Graf, J. S., Littmann, S., Tienken, D., Brand, A., Wehrli, B., et al. (2017). Crenothrix are major methane consumers in stratified lakes. ISME J. 11, 2124-2140. doi: 10.1038/ismej.2017.77

Pandit, P. S., Hoppert, M., and Rahalkar, M. C. (2018). Description of 'Candidatus Methylocucumis oryzae, a novel Type I methanotroph with large cells and pale pink colour, isolated from an Indian rice field. Antonie Van Leeuwenhoek 111, 2473-2484. doi: 10.1007/s10482-018-1136-3

Parks, D. H. (2017). CompareM: a Toolbox for Comparative Genomics. Available at: https://github.com/dparks1134/CompareM [accessed July 3, 2018].

Parks, D. H., Chuvochina, M., Waite, D. W., Rinke, C., Skarshewski, A., Chaumeil, P. A., et al. (2018). A standardized bacterial taxonomy based on genome 
phylogeny substantially revises the tree of life. Nat. Biotechnol. 36, 996-1004. doi: $10.1038 /$ nbt. 4229

Parks, D. H., Rinke, C., Chuvochina, M., Chaumeil, P. A., Woodcroft, B. J., Evans, P. N., et al. (2017). Recovery of nearly 8,000 metagenome-assembled genomes substantially expands the tree of life. Nat. Microbiol. 2, 1533-1542. doi: 10.1038/s41564-017-0012-7

Parte, A. C. (2014). LPSN-list of prokaryotic names with standing in nomenclature. Nucleic Acids Res. 42, D613-D616. doi: 10.1093/nar/gkt1111

Qin, Q. L., Xie, B. B., Zhang, X. Y., Chen, X. L., Zhou, B. C., Zhou, J., et al. (2014). A proposed genus boundary for the prokaryotes based on genomic insights. J. Bacteriol. 196, 2210-2215. doi: 10.1128/JB.01688-14

Rahalkar, M. C., and Pandit, P. (2018). Genome-based insights into a putative novel Methylomonas species (strain $\mathrm{Kb} 3$ ), isolated from an Indian rice field. Gene Rep. 13, 9-13. doi: 10.1016/j.genrep.2018.08.004

Rambaut, A. (2007). FigTree. Available at: http://tree.bio.ed.ac.uk/software/figtree [accessed September 27, 2018].

Ramette, A., and Tiedje, J. M. (2007). Biogeography: an emerging cornerstone for understanding prokaryotic diversity, ecology, and evolution. Microb. Ecol. 53, 197-207. doi: 10.1007/s00248-005-5010-2

Richter, M., and Rosselló-Móra, R. (2009). Shifting the genomic gold standard for the prokaryotic species definition. Proc. Natl. Acad. Sci. U.S.A. 106, 19126-19131. doi: 10.1073/pnas.0906412106

Rosselló-Móra, R., and Amann, R. (2001). The species concept for prokaryotes. FEMS Microbiol. Rev. 25, 39-67. doi: 10.1111/j.1574-6976.2001.tb00571.x

Sieburth, J. M., Johnson, P. W., Eberhardt, M. A., Sieracki, M. E., Lidstrom, M., and Laux, D. (1987). The first methane-oxidizing bacterium from the upper mixing layer of the deep ocean: Methylomonas pelagica sp. nov. Curr. Microbiol. 14, 285-293. doi: 10.1007/Bf01568138

Skennerton, C. T., Ward, L. M., Michel, A., Metcalfe, K., Valiente, C., Mullin, S., et al. (2015). Genomic reconstruction of an uncultured hydrothermal vent gammaproteobacterial methanotroph (family Methylothermaceae) indicates multiple adaptations to oxygen limitation. Front. Microbiol. 6:1425. doi: 10. 3389/fmicb.2015.01425

Smith, G. J., Angle, J. C., Solden, L. M., Borton, M. A., Morin, T. H., Daly, R. A., et al. (2018). Members of the genus Methylobacter are inferred to account for the majority of aerobic methane oxidation in oxic soils from a freshwater wetland. mBio 9:e00815-18. doi: 10.1128/mBio.00815-18

Stamatakis, A. (2014). RAxML version 8: a tool for phylogenetic analysis and post-analysis of large phylogenies. Bioinformatics 30, 1312-1313. doi: 10.1093/ bioinformatics/btu033

Stoecker, K., Bendinger, B., Schöning, B., Nielsen, P. H., Nielsen, J. L., Baranyi, C., et al. (2006). Cohn's Crenothrix is a filamentous methane oxidizer with an unusual methane monooxygenase. Proc. Natl. Acad. Sci. U.S.A. 103, 2363-2367. doi: 10.1073/pnas.0506361103

Strong, P. J., Xie, S., and Clarke, W. P. (2015). Methane as a resource: can the methanotrophs add value? Environ. Sci. Technol. 49, 4001-4018. doi: 10.1021/ es504242n

Tatusova, T., Ciufo, S., Fedorov, B., O’Neill, K., and Tolstoy, I. (2014). RefSeq microbial genomes database: new representation and annotation strategy. Nucleic Acids Res. 42, D553-D559. doi: 10.1093/nar/gkt1274

Thompson, C. C., Amaral, G. R., Campeao, M., Edwards, R. A., Polz, M. F., Dutilh, B. E., et al. (2015). Microbial taxonomy in the post-genomic era: rebuilding from scratch? Arch. Microbiol. 197, 359-370. doi: 10.1007/s00203-014-1071-2
Tindall, B. J., Rosselló-Móra, R., Busse, H. J., Ludwig, W., and Kämpfer, P. (2010). Notes on the characterization of prokaryote strains for taxonomic purposes. Int. J. Syst. Evol. Microbiol. 60, 249-266. doi: 10.1099/ijs.0. 016949-0

Vigliotta, G., Nutricati, E., Carata, E., Tredici, S. M., De Stefano, M., Pontieri, P., et al. (2007). Clonothrix fusca Roze 1896, a filamentous, sheathed, methanotrophic $\gamma$-proteobacterium. Appl. Environ. Microbiol. 73, 3556-3565. doi: 10.1128/AEM.02678-06

Völker, H., Schweisfurth, R., and Hirsch, P. (1977). Morphology and ultrastructure of Crenothrix polyspora Cohn. J. Bacteriol. 131, 306-313.

Wartiainen, I., Hestnes, A. G., McDonald, I. R., and Svenning, M. M. (2006). Methylobacter tundripaludum sp. nov., a methane-oxidizing bacterium from Arctic wetland soil on the Svalbard islands, Norway $\left(78^{\circ} \mathrm{N}\right)$. Int. J. Syst. Evol. Microbiol. 56, 109-113. doi: 10.1099/ijs.0.63728-0

Whitman, W. B. (2011). Intent of the nomenclatural Code and recommendations about naming new species based on genomic sequences. Bull. BISMiS 2, 135-139.

Whitman, W. B., Woyke, T., Klenk, H. P., Zhou, Y., Lilburn, T. G., Beck, B. J., et al. (2015). Genomic Encyclopedia of Bacterial and Archaeal Type Strains, Phase III: the genomes of soil and plant-associated and newly described type strains. Stand. Genomic Sci. 10:26. doi: 10.1186/s40793-015-0017-x

Whittenbury, R., Phillips, K. C., and Wilkinson, J. F. (1970). Enrichment, isolation and some properties of methane-utilizing bacteria. J. Gen. Microbiol. 61, 205-218. doi: 10.1099/00221287-61-2-205

Wirth, J. S., and Whitman, W. B. (2018). Phylogenomic analyses of a clade within the roseobacter group suggest taxonomic reassignments of species of the genera Aestuariivita, Citreicella, Loktanella, Nautella, Pelagibaca, Ruegeria, Thalassobius, Thiobacimonas and Tropicibacter, and the proposal of six novel genera. Int. J. Syst. Evol. Microbiol. 68, 2393-2411. doi: 10.1099/ijsem.0. 002833

Wise, M. G., McArthur, J. V., and Shimkets, L. J. (2001). Methylosarcina fibrata gen. nov., sp. nov. and Methylosarcina quisquiliarum sp. nov., novel Type 1 methanotrophs. Int. J. Syst. Evol. Microbiol. 51, 611-621. doi: 10.1099/ 00207713-51-2-611

Wu, D., Hugenholtz, P., Mavromatis, K., Pukall, R., Dalin, E., Ivanova, N. N., et al. (2009). A phylogeny-driven genomic encyclopaedia of Bacteria and Archaea. Nature 462, 1056-1060. doi: 10.1038/nature08656

Zhang, Y., Kitajima, M., Whittle, A. J., and Liu, W. T. (2017). Benefits of genomic insights and CRISPR-Cas signatures to monitor potential pathogens across drinking water production and distribution systems. Front. Microbiol. 8:2036. doi: $10.3389 /$ fmicb.2017.02036

Conflict of Interest Statement: The authors declare that the research was conducted in the absence of any commercial or financial relationships that could be construed as a potential conflict of interest.

Copyright $\odot 2018$ Orata, Meier-Kolthoff, Sauvageau and Stein. This is an open-access article distributed under the terms of the Creative Commons Attribution License (CC BY). The use, distribution or reproduction in other forums is permitted, provided the original author(s) and the copyright owner(s) are credited and that the original publication in this journal is cited, in accordance with accepted academic practice. No use, distribution or reproduction is permitted which does not comply with these terms. 